\title{
ESTABLECIMIENTO DE ENSAYO DE PLANTACIÓN SUPLEMENTARIA EN BOSQUES ALTERADOS DE ÑIRRE (Nothofagus antárctica (G. Forst.) Oerst.) EN LA REGIÓN DE AYSÉN
}

\author{
Salinas, Jaime²; Acuña, Bernardo y Uribe, Alicia.
}

\section{RESUMEN}

La estructura y dinámica de los bosques de especies del género Nothofagus de Sudamérica están asociadas a disturbios o alteraciones periódicas, tales como volteos por viento, incendios, movimientos de masas y tectonismo. Los disturbios a pequeña escala, donde solo se produce la caída de árboles individuales o de un grupo de ellos, dan lugar a una dinámica de claros.

Los bosques de ñirre (Nothofagus antárctica (G. Forst.) Oerst.) no se alejan de esta dinámica de disturbios, estos ecosistemas durante largo tiempo se asocian a una presión de ganado doméstico, al ataque de insectos por su distribución de transición estepárica y han sido asolados durante décadas por incendios forestales, resultando esto en una perdida estructural, degradación del bosque y un escaso valor comercial.

El ñirre tiene una de las más baja capacidad germinativa del genero Nothofagus, lo cual cual afecta su regeneración natural, la que además debe estar soportando la presencia de ganado, competencia con el sotobosque y periodos secos prolongados. Estos factores hacen peligrar la incorporación y desarrollo de la regeneración. Por lo anterior, lograr identificar prácticas que posibiliten la regeneración natural o técnicas de ayuda a la regeneración con la especie es importante para poder recuperar estos bosques. Este trabajo pretende generar el conocimiento en el proceso de instalación de un ensayo de plantación suplementaria en cluster bajo un gradiente lumínico para fines de producción, recuperación y restauración de estos bosques en el sur austral de Chile.

Palabras clave: Nirre (Nothofagus antárctica), bosques nativos, restauración forestal.

\section{SUMMARY}

Structure and dynamics of Nothofagus species forests in South America are associated to recurring disturbances and changes, such as forest fires, wind damages, mass movements and tectonics. Small scale disturbances, producing individual trees or small stands falls, drive to a dynamic of forest clearings.

Nirre (Nothofagus antarctica) forests are not the exception and for a long time have been associated to different pressures because of ranching, forest fires, insect attacks and other pressuring factors. As a result, most of the remaining forests have lost their structure and commercial value.

The Nirre has one of the lowest germination capacity of the Nothofagus genus, affecting y its natural regeneration, which also must be supporting the presence of livestock, competition with the understory and prolonged dry periods. These factors restrict natural regeneration incorporation and development. Therefore, to identify practices that enable natural regeneration or techniques to help regeneration with the species is important to recover these forests. This work attempt to generate knowledge in the process by installing a trial of supplementary planting in clusters under a light gradient for production, recovery and restoration of these forests in southern Chile.

Keywords: Nirre (Nothofagus antárctica), native forests, forest restoration

${ }^{2}$ Instituto Forestal, Sede Patagonia, Coyhaique. jsalinas@infor.cl 


\section{INTRODUCCIÓN}

Ñirre (Nothofagus antárctica (G. Forst.) Oerst) es una especie del bosque nativo que crece principalmente en las zonas cordilleranas de Chile y Argentina. Es una de las especies forestales con mayor plasticidad ecológica. Su expresión fenotípica. que depende principalmente del sitio donde se desarrolla, fue clasificada en tres morfotipos; arborescente, achaparrado y camefítico (Ramírez et al., 1985). Los bosques de ñirre están clasificados dentro del Tipo Forestal Lenga, y descritos informalmente en el Subtipo Nirre que representa una superficie de 131.593,4 ha en la Región de Aysén (Salinas et al., 2017).

Estas formaciones están presentes en la mayoría de las comunas de la Región de Aysén a excepción de la comuna costera de Las Guaitecas. Las mayores poblaciones de ñirre se sitúan en las Provincias de Coyhaique y Capitán Prat, con $61.630,6$ ha y $37.241,3$ ha, respectivamente (Salinas, 2016).

En el área de distribución natural de los ñirrantales la actividad forestal convive con la ganadera, con importantes áreas de resguardo de ganado en épocas invernales y alta presión para la obtención de leña. Un porcentaje importante de los cerca de $500.000 \mathrm{~m}^{3}$ de leña que se consumen anualmente en la Región de Aysén proviene de los bosques de ñirre.

La leña de esta especie es preferida por su alto poder calórico $\left(2.850 \mathrm{kcal} / \mathrm{dm}^{3}\right)$, en comparación con lenga $\left(2.400 \mathrm{kcal} / \mathrm{dm}^{3}\right)$. Esta es una situación que preocupa, dado que estos ecosistemas solo bajo técnicas de manejo apropiadas pueden continuar produciendo a perpetuidad.

En el plano regional el subtipo ñirre ocupa cerca del $37,4 \%$ de la superficie. En la mayor parte de estos ecosistemas existe la presencia de ganado. Se suma a este factor de disturbio el bajo poder germinativo de las semillas de esta especie. Salinas et al. (2016) encontraron el mayor poder germinativo registrado para ñirre en el territorio nacional, bajo un tratamiento de estratificación en arena fría por 45 días alcanzando un $28 \%$ de capacidad germinativa. Nirre tiene también la capacidad de regenerar de forma agámica, posiblemente una adaptación de la especie a una historia constante de incendios forestales.

Lograr identificar prácticas que posibiliten la regeneración natural o el desarrollo de técnicas de plantación suplementaria con la especie es importantes para que estos bosques no sigan degradándose por disturbios naturales y antrópicos. En el desarrollo de la línea de investigación de INFOR, de mediano y largo plazo, denominada "Tratamientos Silvícolas para el Bosque Nativo con Enfoque Ecosistémico: Técnicas silvícolas que favorecen la regeneración de ecosistemas forestales en Chile", se propuso instalar ensayos que generen conocimiento para el establecimiento adecuado de plantas de ñirre para fines de producción, recuperación y restauración ecológica de estos bosques en el sur austral de Chile.

\section{ANTECEDENTES DE LA ESPECIE}

Nirre es un árbol nativo presente en Chile y Argentina, es una especie monoica que se presenta como árbol pequeño o arbusto achaparrado, aunque generalmente alcanza los $10 \mathrm{~m}$ de altura. Sin embargo, en condiciones óptimas de sitio puede alcanzar los $15 \mathrm{~m}$ y diámetros de $60 \mathrm{~cm}$ (Rodríguez et al., 1983; Donoso, 1974).

Salinas et al. (2015) reportan alturas cercanas a los $23 \mathrm{~m}$ en suelos profundos de la comuna de Chile Chico, Región de Aysén. En esta región puede asociarse con lenga (Nothofagus pumilio (Poepp. \& Endl.)), pero generalmente forma bosques puros y coetáneos denominados ñirrantales.

Nirre es considerada la especie de género Nothofagus de Sudamérica con mayor variación morfológica y mayor plasticidad ecológica, y se distinguen tres morfotipos en el territorio nacional (Ramírez et al., 1985) (Figura №1). 


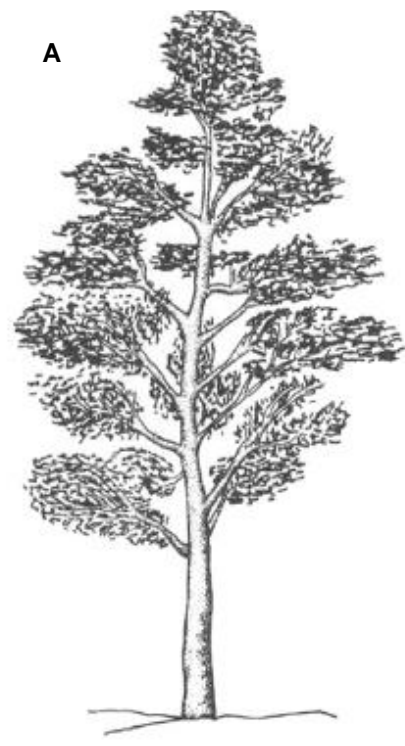

\begin{abstract}
A. Arbóreo
Crece en condiciones óptimas, sobre suelos con mayor profundidad que permiten a la raíz mayor distancia de exploración por nutrientes. La condición de humedad también es más favorable.
\end{abstract}

B. Arbustivo o Achaparrado

Crece en terrenos pedregosos, suelos delgados o clima riguroso.

Zonas con acumulación de agua por mal drenaje.

\title{
C. Camefítico
}

Común de zonas anegadas en forma permanente, las raíces no logran desarrollarse por falta de oxígeno.

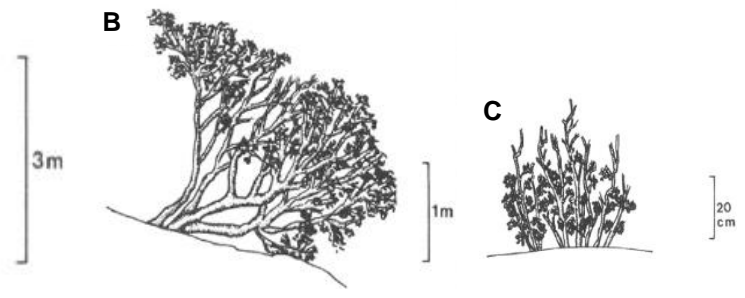

Figura $\mathrm{N}^{\circ} 1$

MORFOTIPOS DE ÑIRRE EN CHILE

La corteza del ñirre es de color gris, rugosa, áspera y muy agrietada longitudinalmente en forma irregular (Figura $\mathrm{N}^{\circ}$ 2). Presenta hojas pequeñas $(0,6$ a $3,5 \mathrm{~cm}$ de largo), aovadoredondeadas a oblongas, con base acorazonada; bordes finamente dentados, lobulados y ondulados que cambian de tonalidad durante el año. Presenta flores femeninas y masculinas, y frutos formados por 3 nueces, de las cuales 2 son triangulares, las que rodean a una plana que se sitúa en el centro (Hoffmann, 1997).

En los hábitats más favorables, protegidos del viento, con mayor humedad y suelos bien drenados y fértiles, alcanza porte arbóreo, y puede dar lugar a formaciones puras (Navarro Cerrillo et al., 2008). Sin embargo, también muestra un buen desempeño en suelos anegados, como señala Donoso (1987).

En suelos ñadis del llano central puede crecer en condiciones óptimas. En la Patagonia, el ñirre domina las tierras bajas, zonas de valles y aquellos terrenos que han sido perturbados por incendios o ganado (Armesto et al., 1992).

La especie se puede desarrollar en variados ambientes, con diferentes condiciones de sitio. En sitios óptimos, con suficiente humedad y bien drenados, en donde los suelos son fértiles y las variaciones de temperaturas anuales y diarias son moderadas, esta especie crece sin mayores problemas, adquiriendo hábito arbóreo.

No obstante, es posible que el ñirre crezca en suelos con variaciones hídricas amplias a lo largo del año, pobres en fertilidad y pedregosos, en zonas alto andinas y en el ecotono bosqueestepa, donde presenta un crecimiento de menor altura, y en sitios de extrema humedad y mal drenaje adopta progresivamente carácter de planta achaparrada o Krummholz (Ramírez et al., 1985; Veblen et al., 1996; Donoso, 2006).

En cuanto al sustrato característico de los bosques de ñirre desarrollados en la Cordillera 
de los Andes, crece en los límites altitudinales de la vegetación arbórea, formando bolsones de frio, en sustratos pobres en fertilidad y pedregosos, muy secos o húmedos dependiendo de la pendiente.
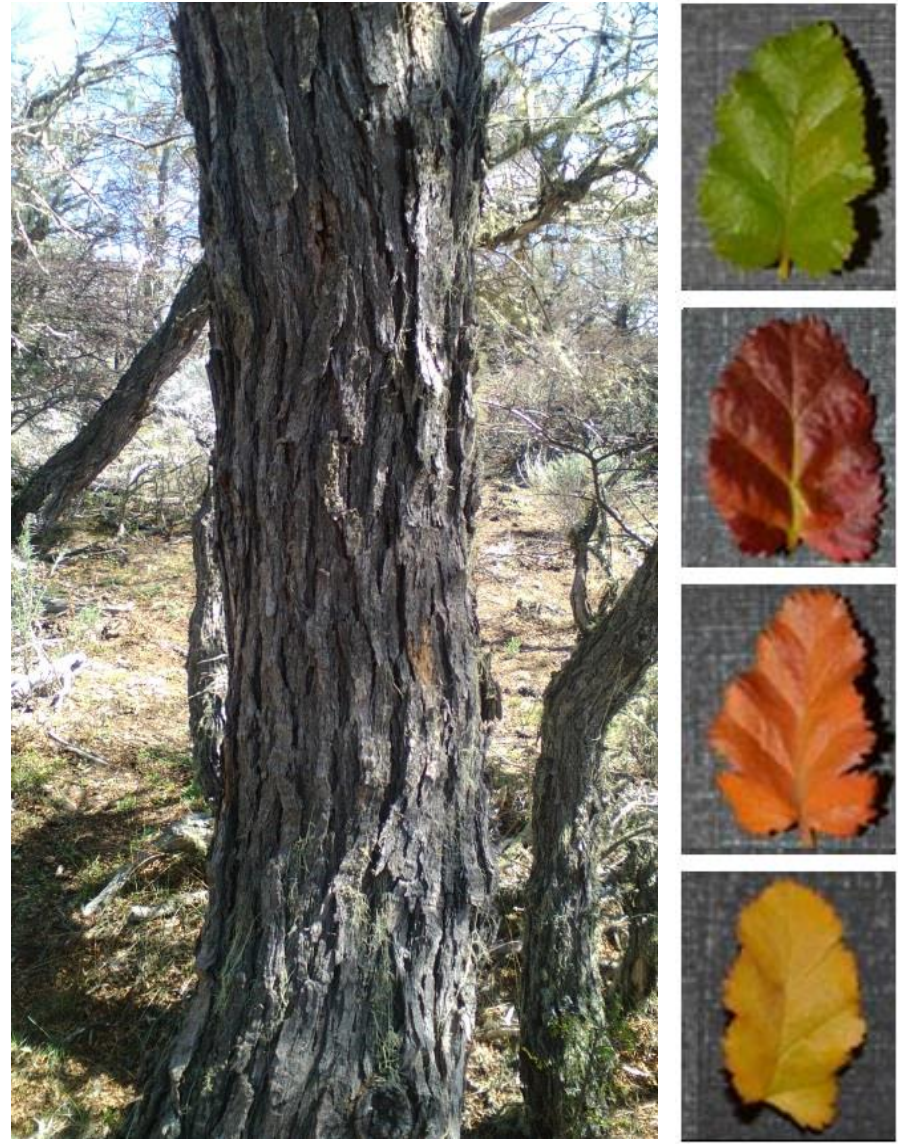

Figura $\mathrm{N}^{\circ} 2$

CORTEZA DE ÑIRRE Y DECOLORACIÓN ESTACIONAL DE HOJAS DE ÑIRRE SECTOR BALMACEDA, REGIÓN DE AYSÉN

En la Depresión Central se desarrolla sobre terrenos planos y suelos conocidos como ñadis, suelos de cenizas volcánicas superficiales que presentan a poca profundidad un hardpan de fierrillo que determina las variaciones hídricas del sitio.

En la zona austral de Magallanes y Tierra del Fuego se encuentra en zonas ecotonales entre el bosque y la estepa, y en morrenas de los sectores de glaciaciones. Se le encuentra también en los límites de la vegetación arbórea. En todos estos casos con condiciones de drenaje restringido, bajas temperaturas y fuertes vientos (Premoli, 1991; Vidal y Premoli, 2004). 


\section{OBJETIVOS}

\section{Objetivo General}

Evaluar el desempeño de plantas de ñirre en diferentes condiciones de bosques, naturales y alterados.

\section{Objetivos Específicos}

Identificación y caracterización sitios para el establecimiento de ensayos de plantación suplementaria en la Región de Aysén.

Elaborar un diseño experimental para el establecimiento de las plantaciones de ñirre y establecer un ensayo de plantación suplementaria en bosques de ñirre alterados.

Monitorear el desempeño de plantaciones de ñirre en diferentes condiciones ambientales.

\section{METODOLOGÍA}

\section{Recopilación de Información}

La metodología se basa en la recopilación de información de trabajos relacionados con ecología, métodos de plantación, recuperación y restauración de bosques de ñirre, información que fue recopilada desde fuentes primarias y secundarias, visitando bibliotecas digitales (http://www.beic.cl/), biblioteca de INFOR (http://biblioteca.infor.cl/index.asp) y otras fuentes en espacio web. En paralelo, se plantea mantener y evaluar unidades establecidas en años anteriores.

\section{Ubicación de los Ensayos}

Para la elección del terreno para el establecimiento del ensayo se utilizó una imagen satelital de la zona de Balmaceda (comuna de Coyhaique, Región de Aysén). Se llevó a cabo una superposición de una capa de los bosques de ñirre de la comuna de Coyhaique realizada por Salinas et al. (2016) y una segunda capa de propietarios de la comuna de Coyhaique, con el fin de definir los posibles candidatos a entrevistar para seleccionar el lugar del ensayo.

Se escogió un ñirrantal en las cercanías de la localidad de Balmaceda, en una condición seca, cercana a la transición con la estepa, sin influencia de napa freática, lugar denominado Galera Chico (GCh).

En este sitio se trabajará en diferentes condiciones de cobertura; un Testigo o Bosque sin Manejo, un Bosque con Manejo en el que se aplicó un raleo por lo bajo extrayendo alrededor del $40 \%$ del área basal y un tercer tratamiento en terreno abierto de Pradera Naturalizada resultante de una extracción anterior del bosque para el uso ganadero del terreno.

\section{Caracterización de la Estructura Forestal}

En las situaciones de bosque se caracterizó la estructura forestal a través de 3 parcelas circulares de diámetro fijo con una superficie de $200 \mathrm{~m}^{2}$.

En cada uno de los árboles contabilizados en cada parcela de inventario se midieron las siguientes variables individuales:

- Diámetro a la Altura del Pecho (DAP) a 1,30 m de altura (cm).

- Espesor de Corteza (EC) (mm).

- Altura total $(\mathrm{HT})(\mathrm{m})$. 
- Clase Social (CS): Posición relativa y tamaño de la copa de cada individuo en el estrato vertical, clasificándolos en dominantes, codominantes, intermedios y suprimidos.

Dominante: Aquellos individuos cuyas copas se extienden en el nivel general del dosel superior, recibiendo plena luz desde arriba y parcialmente de los lados. Sus copas son bien desarrolladas.

Codominante: Aquellos individuos cuyas copas constituyen el nivel general del vuelo y reciben plena luz desde arriba y se presentan más comprimidas lateralmente en relación con los dominantes.

Intermedio: Aquellos individuos de copas comprimidas que apenas alcanzan el dosel y reciben escasa luz solar directa.

Suprimido: Aquellos individuos cuyas copas se encuentran completamente por debajo del dosel y no reciben luz solar directa.

- Forma (F): Clasificada como mala, regular o buena.

Buena: Individuos rectos a lo largo de todo su fuste y aquellos individuos que poseen pequeñas curvaturas que no impiden la obtención de postes.

Regular: Individuos con defectos de forma (ganchos, bifurcaciones, curvaturas o inclinaciones) que permiten obtener al menos un poste de 2,2 $\mathrm{m}$.

Mala: Individuos con defectos de forma generalizados que no permiten la obtención de postes.

- Sanidad Externa (SE): Clasificada como mala, regular o buena dependiendo de la ocurrencia en el fuste de defectos generalizados, localizados 0 ausentes, respectivamente. Los defectos incluyen tanto agallas, como cancros, cavidades, rajaduras o daños producidos por la actividad de insectos o pájaros carpinteros.

- Estado de Desarrollo (ED): La clasificación de la fase de desarrollo se determinará a partir de una adaptación para ñirre de la clasificación propuesta de Schmidt y Urzúa (1982). Para dicha clasificación se observa la corteza en el fuste a 1,30 m de altura.

Crecimiento óptimo inicial (COI): Individuos con corteza lisa, sin grietas y las lenticelas a la vista.

Crecimiento óptimo final (COF): Individuos con corteza de grietas poco profundas que conserva vestigios de la corteza COI entre grietas.

Envejecimiento (E): Individuos cuya corteza presenta grietas de mayor profundidad que los individuos COF.

Desmoronamiento (D): Individuos cuya corteza de grietas profundas adquiere una apariencia corchosa, pudiendo observarse desprendimientos de placas de corteza.

- Cobertura de Copas (CC) (\%): Considerando los siguientes rangos; 1 . menos de $25 \%$; 2. 25 a $50 \%$; 3.50 a $75 \%$ y 4 . más de $75 \%$.

Con los resultados de la medición individual de los árboles se estimaron las siguientes variables de rodal:

Altura Dominante (HD): Se calcula como el promedio de la altura total de los individuos dominantes presentes en cada parcela. 
Diámetro Cuadrático Medio (DCM).

Área Basal $(A B)\left(m^{2} / h a\right)$.

Densidad (N): (árb/ha).

Volumen total con corteza (VTCC): Se estima a partir de los volúmenes individuales utilizando una ecuación estándar tradicional (Ivancich, 2013) que predice el volumen total con corteza para un diámetro mínimo de $5 \mathrm{~cm}$.

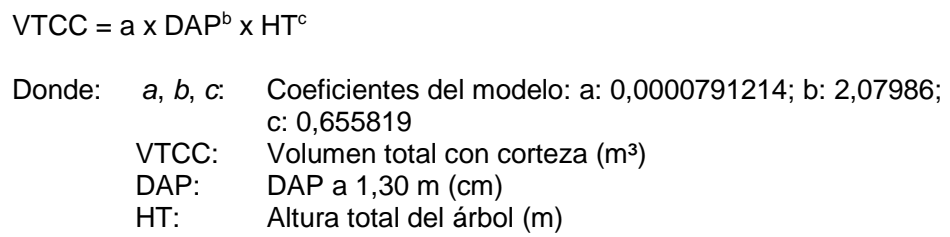

\section{Diseño Experimental del Ensayo}

En cada uno de los tratamientos descritos anteriormente; Testigo o Bosque sin Manejo, Bosque con Manejo en el que se aplicó un raleo por lo bajo extrayendo alrededor del $40 \%$ del área basal y terreno abierto de Pradera Naturalizada, se establecieron tres clausuras rectangulares de $10 \times 20 \mathrm{~m}$, protegidas por cercos con malla hexagonal para evitar daños por bovinos y lagomorfos.

Al interior de cada clausura se establecen plantas de ñirre en clusters, agrupando un total de 5 plantas por cluster (Figura $\mathrm{N}^{\circ} 3$ ), y en cada clausura se establece un total de 40 clusters ( $\mathrm{N}=200$ plantas). Previo al establecimiento se controlaron las malezas de forma manual.

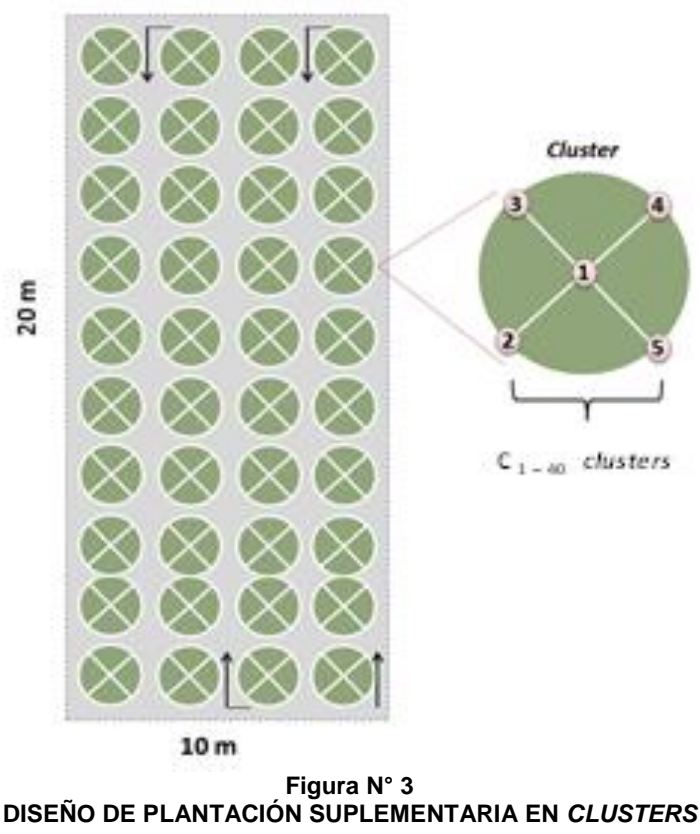


Cada planta en los clusters es individualizada para registrar anualmente las siguientes variables: Diámetro altura del cuello (DAC) $(\mathrm{mm})$, Altura total $(\mathrm{cm})$, Supervivencia $(\%)$ y Ramoneo (presente y ausente), a partir del segundo año.

Además, se registran algunas variables climáticas del sitio (temperatura ambiental precipitación, humedad ambiental y velocidad del viento), con la instalación de estaciones meteorológicas móviles, y variables más específicas con el uso de dataloggers (humedad suelo) y penetrómetro (compactación de suelo). tratamiento.

También se utilizan fotografías hemisféricas para evaluar parámetros lumínicos de cada

\section{Análisis Estadístico}

Preliminarmente se realizará un análisis de varianza para probar potenciales diferencias en crecimiento de la plantación bajo cobertura. Las variables respuestas serán el crecimiento en DAC $(\mathrm{cm})$, altura $(\mathrm{cm})$ y volumen individual $\left(\mathrm{cm}^{3} /\right.$ planta). La variable independiente serán los tratamientos silvícolas (testigo, silvopastoral y pradera naturalizada.

Un análisis más detallado se realizará a nivel de planta individual. El crecimiento (DAC, altura y volumen) será modelado por medio de regresión lineal múltiple. Como predictores se utilizará la disponibilidad de luz (\% transmitido), el contenido de humedad de suelo (\%) y la resistencia a la penetración ( $\mathrm{MPa})$. Como variable indicadora se utilizarán los tratamientos silvícolas $(n=3)$.

Para el potencial ramoneo se utilizará regresión logística para variables binarias (presente y ausente) con una extensión Logit. El ramoneo será modelado utilizando la disponibilidad de luz, el contenido de humedad de suelo y la resistencia a la penetración, y sus interacciones como predictores.

Todos los análisis serán realizados usando un nivel de confianza de un 95\%.

\section{RESULTADOS}

\section{Evaluación de la Estructura Forestal}

La edad media del rodal del sector Galera Chico se determinó a través de la corta de rodelas a diferentes alturas, posteriormente se procedió a cuantificar los anillos de crecimiento de árboles cuyos diámetros se distribuían entre 9 y $32 \mathrm{~cm}$. Con este análisis se determinó la edad del rodal, que fluctúa entre 32 y 77 años, con un promedio de 50 años.

Cuadro $\mathrm{N}^{\circ} 1$

CARACTERIZACIÓN DEL MUESTREO PARA LA DETERMINACIÓN DE LA EDAD DEL BOSQUE

\begin{tabular}{|c|c|c|c|}
\cline { 2 - 4 } \multicolumn{1}{c|}{} & $\begin{array}{c}\text { DAP } \\
(\mathbf{c m})\end{array}$ & $\begin{array}{c}\mathbf{H}_{\text {tot }} \\
(\mathbf{m})\end{array}$ & $\begin{array}{c}\text { Edad } \\
\text { (años) }\end{array}$ \\
\hline Media & 18,29 & 9,44 & 50 \\
Min & 9,20 & 5,75 & 32 \\
Max & 32,50 & 12,80 & 77 \\
$\mathrm{~S}_{\mathrm{y}}{ }^{2}$ & 42,62 & 3,68 & \\
$\mathrm{~S}_{\mathrm{y}}$ & 6,53 & 1,92 & \\
$\mathrm{~S}_{\mathrm{y}}(\%)$ & 0,36 & 0,20 & \\
\hline
\end{tabular}


En cada situación con bosque de ñirre, se realiza anualmente un seguimiento de la respuesta al raleo, realizando una comparación de las situaciones originales y de los bosques con intervención silvícola.

Esta evaluación se realizó sobre 3 parcelas permanentes circulares de $200 \mathrm{~m}^{2}$ (radio= $7,98 \mathrm{~m}$ ) que fueron instaladas en cada tratamiento anteriormente.

$\mathrm{m})$.

Cada árbol de la parcela fue identificado, numerado y marcado a la altura del DAP (1,3

Para la obtención de la información dasométrica de cada árbol se midieron las variables altura total y de comienzo de copa utilizando Vertex, el DAP con forcípula, la sanidad (buena, mala, regular), la forma (buena, mala, regular), las clases de copa (dominantes, codominantes, intermedios y suprimidos), el espesor de corteza utilizando calibrador y, finalmente, la regeneración natural a través de 4 sub parcelas de $1 \mathrm{~m}^{2}$ distribuidas en los sentidos cardinales (N, S, E, O).

\section{Cuadro $\mathrm{N}^{\circ} 2$ \\ PROMEDIOS Y DESVÍOS DE LAS VARIABLES DE ESTRUCTURA FORESTAL DE LAS PARCELAS PERMANENTES}

\begin{tabular}{|c|c|c|c|c|c|c|}
\hline Tratamiento & Año & $\begin{array}{c}\mathrm{N} \\
\text { (árb/ha) }\end{array}$ & $\begin{array}{l}\text { DCM } \\
\text { (cm) }\end{array}$ & $\begin{array}{l}\text { HD } \\
(m)\end{array}$ & $\begin{array}{c}A B \\
\left(\mathrm{~m}^{2} / \mathrm{ha}\right)\end{array}$ & $\begin{array}{l}\text { VTCC } \\
\left(\mathrm{m}^{3} / \mathrm{ha}\right)\end{array}$ \\
\hline \multirow{4}{*}{ Bosque sin Manejo } & \multirow{2}{*}{2015} & 6.717 & 9,4 & 9,8 & 45,9 & 231,4 \\
\hline & & \pm 1415 & $\pm 0,9$ & $\pm 0,6$ & $\pm 4,6$ & $\pm 37,6$ \\
\hline & \multirow{2}{*}{2016} & 6.633 & 9,5 & 10,1 & 46,6 & 235,5 \\
\hline & & \pm 1407 & $\pm 0,8$ & $\pm 0,7$ & $\pm 4,9$ & $\pm 36,4$ \\
\hline \multirow{4}{*}{ Bosque con Manejo } & \multirow{2}{*}{2015} & 1.483 & 13,1 & 9,6 & 20,3 & 104,3 \\
\hline & & \pm 153 & $\pm 0,7$ & $\pm 1,5$ & $\pm 4,3$ & $\pm 32,5$ \\
\hline & \multirow{2}{*}{2016} & 1.483 & 13,7 & 10,2 & 22,1 & 115,2 \\
\hline & & \pm 144 & $\pm 1,0$ & $\pm 1,2$ & $\pm 5,4$ & $\pm 39,9$ \\
\hline
\end{tabular}

N: Densidad, AB: Área basal; DCM: Diámetro cuadrático medio;

HD: Altura dominante; VTCC: Volumen total con corteza.

La densidad del Bosque sin Manejo fue de 6.717 árb/ha, una densidad común de encontrar en renovales de ñirre de mediana edad como este.

Es importante considerar la tasa de mortalidad natural del ñirre producto de la competencia intraespecífica, que para la temporada de un año de evaluación fue de 84 árb/ha para el bosque sin intervención comparado con el bosque raleado donde no se observó muerte natural. 

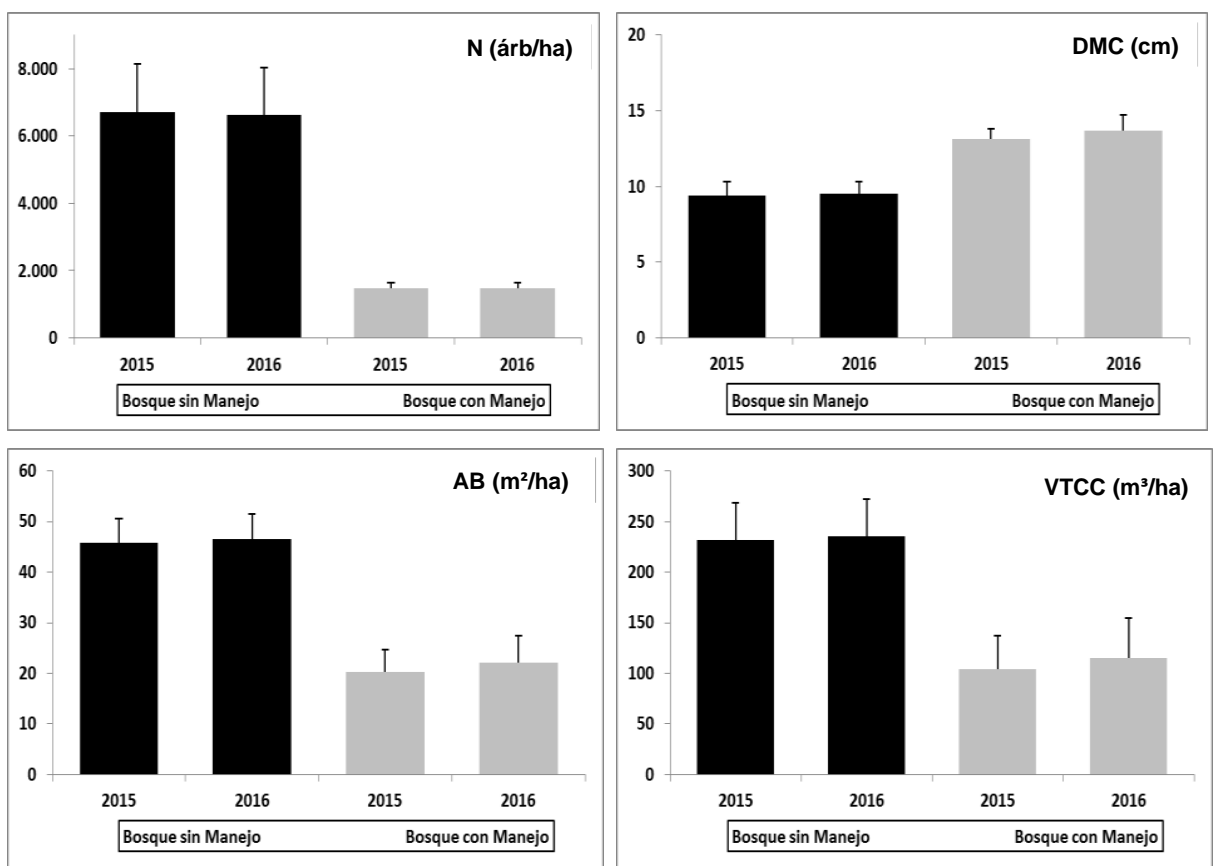

Figura $\mathrm{N}^{\circ} 3$

PROMEDIOS Y DESVÍOS DE LAS VARIABLES DE ESTRUCTURA FORESTAL BOSQUE CON Y SIN MANEJO TEMPORADA $2015-2016$

Cuadro $\mathrm{N}^{\circ} 3$

INCREMENTO EN DIÁMETRO, ÁREA BASAL Y VOLUMEN POR TRATAMIENTO

\begin{tabular}{|lccc|}
\hline Tratamiento & $\begin{array}{c}\text { Inc DMC } \\
\mathbf{( c m})\end{array}$ & $\begin{array}{c}\text { Inc AB } \\
\left(\mathbf{m}^{\mathbf{2}} / \mathbf{h a}\right)\end{array}$ & $\begin{array}{c}\text { Inc VTTC } \\
\left(\mathbf{m}^{\mathbf{3}} / \mathbf{h a}\right)\end{array}$ \\
\hline \multirow{2}{*}{ Bosque sin Manejo } & 0,13 & 0,74 & 4,12 \\
& $\pm 0,10$ & $\pm 0,8$ & $\pm 3,8$ \\
\hline \multirow{2}{*}{ Bosque con Manejo } & 0,57 & 1,87 & 10,88 \\
& $\pm 0,3$ & $\pm 1,1$ & $\pm 7,4$ \\
\hline
\end{tabular}

La evaluación de parcelas permanentes de Bosque con Manejo mostró una favorable respuesta al raleo.

El incremento en diámetro cuadrático medio fue $438 \%$ superior al encontrado en el Bosque sin Manejo, mientras que el incremento en la situación con manejo en términos de AB y en VTCC fue $253 \%$ y $264 \%$ superior, respectivamente, al encontrado en el Bosque sin Manejo. 


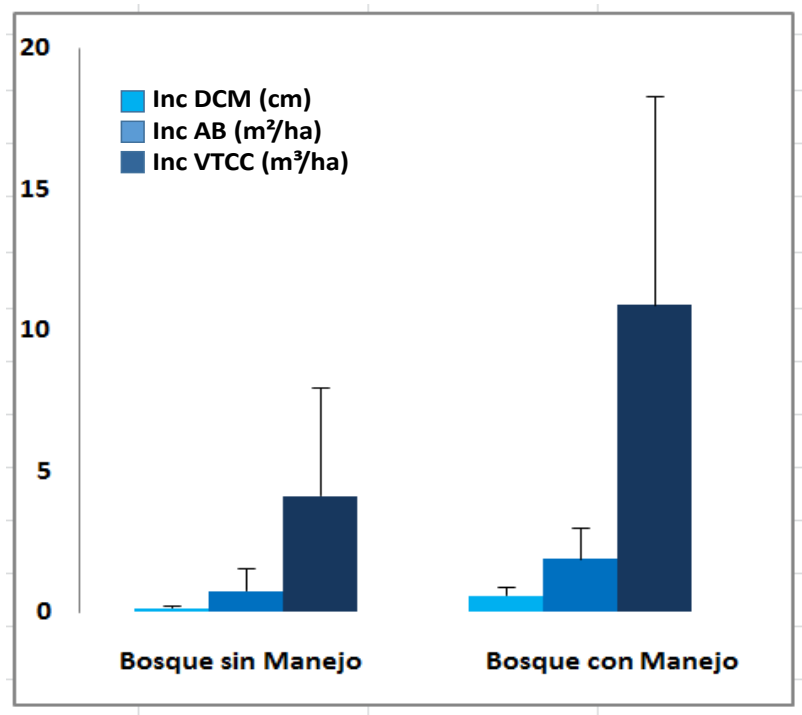

Figura $N^{\circ} 4$

PROMEDIOS Y DESVÍOS DEL INCREMENTO ANUAL EN DIÁMETRO, ÁREA BASAL Y VOLUMEN

En el Cuadro $\mathrm{N}^{\circ} 4$ se presenta la participación porcentual de los tratamientos por estado de desarrollo en relación al diámetro medio cuadrático (DMC). La anterior clasificación es usada para otros Tipos Forestales que difieren mucho de los bosques de ñirre (Ej. Lenga), por lo que es necesario crear una clasificación individual para este tipo de bosques, que responda no solo a las variables dasométricas, sino que más bien incorpore otras variables del sitio.

En el cuadro mencionado se clasifica el Bosque sin Manejo en su mayoría como Brinzal Alto. Por otro lado, el tratamiento de Bosque Manejado fue clasificado en un $100 \%$ como Latizal Bajo.

Cuadro $\mathrm{N}^{\circ} 4$

CLASIFICACIÓN DEL ESTADO DE DESARROLLO

A TRAVÉS DE LA PARTICIPACIÓN PORCENTUAL DEL DMC EN CADA TRATAMIENTO

\begin{tabular}{|c|c|c|c|c|c|c|c|}
\hline \multirow[t]{2}{*}{ Estado de Desarrollo } & & \multirow{2}{*}{\multicolumn{2}{|c|}{$\begin{array}{c}\text { Rango DMC } \\
(\%)\end{array}$}} & \multicolumn{2}{|c|}{$\begin{array}{l}\text { Bosque } \\
\text { sin } \\
\text { Manejo } \\
(\%)\end{array}$} & \multicolumn{2}{|c|}{$\begin{array}{c}\text { Bosque } \\
\text { con } \\
\text { Manejo } \\
(\%)\end{array}$} \\
\hline & & & & 2015 & 2016 & 2015 & 2016 \\
\hline Repoblado & & & & - & - & - & - \\
\hline \multirow[t]{2}{*}{ Brinzal } & Bajo & & & - & - & - & - \\
\hline & Alto & & $\leq 10$ & 100 & 66,7 & - & - \\
\hline \multirow{2}{*}{ Latizal } & Bajo & $>10$ & $\leq 20$ & & 33,3 & 100 & 100 \\
\hline & Alto & $>20$ & $\leq 30$ & - & - & - & - \\
\hline \multirow{2}{*}{ Fustal } & Joven & $>30$ & $\leq 50$ & - & - & - & - \\
\hline & Fustal & $>50$ & $\leq 70$ & - & - & - & - \\
\hline Sobremaduro & & $>70$ & & - & - & - & - \\
\hline
\end{tabular}


La clase social de las copas se presenta en la Figura $N^{\circ} 5$, donde es posible diferenciar gráficamente cada clase de copas para orientar la intervención silvícola futura. El tratamiento del Bosque con Manejo posee una menor proporción de individuos suprimidos no superando el $7 \%$ de participación, hecho contrario ocurre en el tratamiento con cobertura completa (Bosque sin Manejo) donde ocurre una mayor proporción de individuos suprimidos de $15 \%$. Existe una alta proporción de la clase social Intermedio en ambos tratamientos cercanos al $60 \%$ y una menor proporción de árboles dominantes cercano a 1/3 del total.

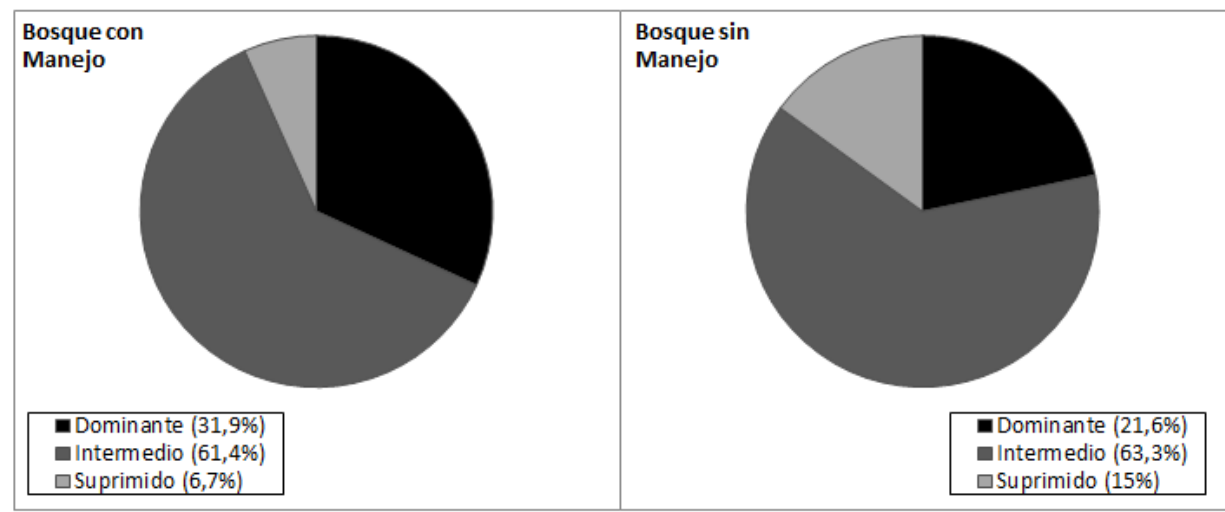

Figura $N^{\circ} 5$

PARTICIPACIÓN DE LA POSICIÓN RELATIVA DE LAS COPAS EN LOS BOSQUES CON Y SIN MANEJO

\section{Caracterización del Área de Estudio}

El ensayo se estableció en las cercanías de Balmaceda, en un sector denominado Galera Chico en la comuna de Coyhaique, en este lugar existe un ñirrantal en una condición seca, ubicado en un sitio de transición de estepa, sin influencia de napa freática. El predio se denomina Los Mallines y es de propiedad del Sr. Claudio Bambs, coordenadas $45^{\circ} 50^{\prime} \mathrm{S}-71^{\circ} 49^{\prime} \mathrm{O}$.

La situación de estudio escogida se encuentra en la zona de transición con la estepa patagónica. Se trata de bosques puros y coetáneos, el morfotipo presente es arbóreo, aunque en esta zona ecotonal es común encontrar el morfotipo arbustivo relegado a suelos someros de bajo contenido nutricional. Los suelos de estos sectores cercanos a la localidad de Balmaceda corresponden a formaciones de Xerolls, que se caracterizan por estar bien drenados (gran grupo Haploxerolls). En posiciones bajas con problemas de drenaje se encuentran suelos Inceptisols (Gran Grupo Haplaquepts).

\section{Clima}

Esta zona se caracteriza por presentar un clima de estepa fría de vertiente oriental de los Andes Patagónicos o Transandinos y está protegida por el cordón montañoso de la cordillera, la que permite una disminución notable de las precipitaciones en comparación con el sector de archipiélagos (clima oceánico) que se encuentran en la misma latitud. En el lado oriental los valores de las precipitaciones bajan hasta $621 \mathrm{~mm}$ anuales en Balmaceda.

Se registraron las variables climáticas imperantes a través de la estación meteorológica permanente Vista Hermosa ubicada a $10 \mathrm{~km}$ del sitio de estudio. Las variables registradas por los equipos meteorológicos fueron temperatura media del aire y precipitaciones (Figuras $\mathrm{N}^{\circ} 6$ y $\mathrm{N}^{\circ} 7$ ). La información meteorológica se obtuvo del sitio web Agromet de la Red Agrometeorológica de INIA (http://agromet.inia.cl). 

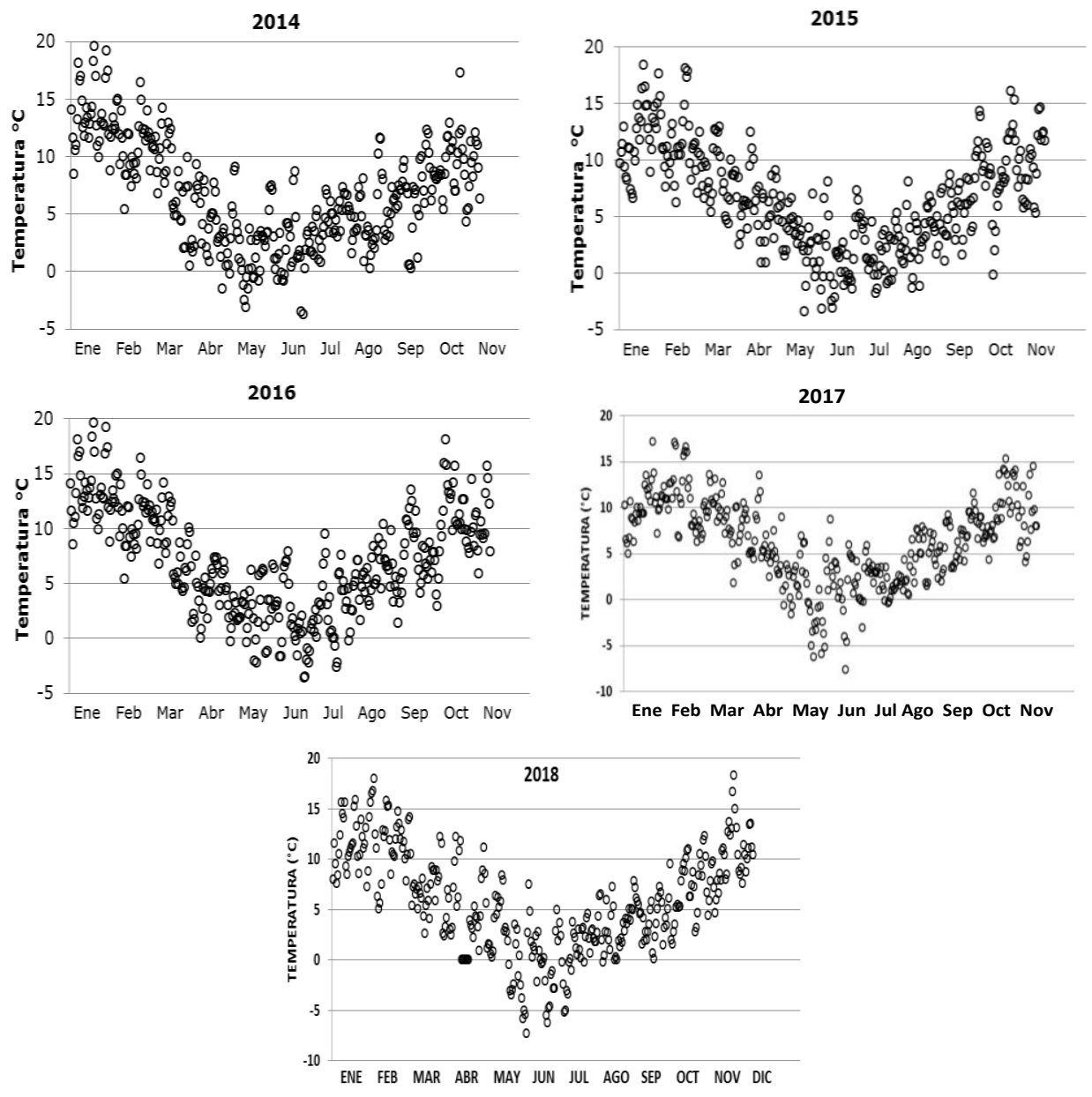

(Fuente: elaboración propia desde http://agromet.inia.cl)

Figura $\mathbf{N}^{\circ} 6$

TEMPERATURAS TEMPORADAS 2014 A 2017 ESTACIÓN METEOROLÓGICA VISTA HERMOSA

De acuerdo a la clasificación de Köppen, el clima de la Región de Aysén corresponde a Trasandino con Degradación Esteparia y se caracteriza por un volumen de precipitaciones y por potencia de los vientos de gran intensidad.

La temperatura media y media mínima anual es de $8,7{ }^{\circ} \mathrm{C}$ y $3,9{ }^{\circ} \mathrm{C}$, respectivamente (máxima de enero es de $18,7^{\circ} \mathrm{C}$ y mínima de julio es de $-0,7^{\circ} \mathrm{C}$ ).

La precipitación media es de $1.200 \mathrm{~mm}$, (IREN, 1979), con un periodo corto de escasez de precipitación entre enero y febrero. Los vientos promedios fluctúan entre 37 y $56 \mathrm{~km} / \mathrm{h}$, con ráfagas de 60 - $80 \mathrm{~km} / \mathrm{h}$ en época de primavera. 


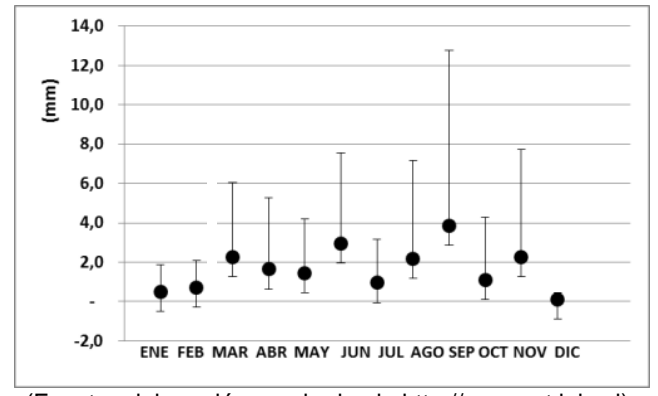

(Fuente: elaboración propia desde http://agromet.inia.cl)

Figura $\mathbf{N}^{\circ} 7$

PRECIPITACIÓN ANUAL ESTACIÓN METEOROLÓGICA VISTA HERMOSA

La temperatura muestra una marcada tendencia a medias mensuales inferiores a $10^{\circ} \mathrm{C}$ gran parte del año. Durante los períodos de evaluación de ensayos, la temperatura media anual del año 2018 fue de $5,9^{\circ} \mathrm{C}$. Las temperaturas mínimas se presentaron en los meses de junio y julio con promedios de $-0,5$ y $-0,4^{\circ} \mathrm{C}$, respectivamente.

Si bien la temperatura podría generar una disminución de la temperatura del bosque por convección, la estructura del bosque y del suelo permite la mantención de estas un poco más altas y permitir el desarrollo y crecimiento normal para las especies adaptadas a estas condiciones del ambiente.

El mes de septiembre fue el mes del año con mayor precipitación acumulada de la temporada, con un valor de $116 \mathrm{~mm}$.

En general, las precipitaciones en zonas de transición esteparia son bajas, aun así, en situaciones donde ñirre se desarrolla en mallines, con presencia de un hardpan de fierrillo, se generan condiciones restringidas de drenaje y acumulación de agua (producto del derretimiento de nieve en las cumbres de montañas), lo que, sumado a las bajas temperaturas y la fuerza del viento, convierte estos ambientes en lugares inhóspitos para el desarrollo de masas boscosas. Sin embargo, la plasticidad fenotípica observada en ñirre permite su adaptación y desarrollo en este tipo de condiciones ambientales, en las cuales otras especies del género Nothofagus no prosperarían.

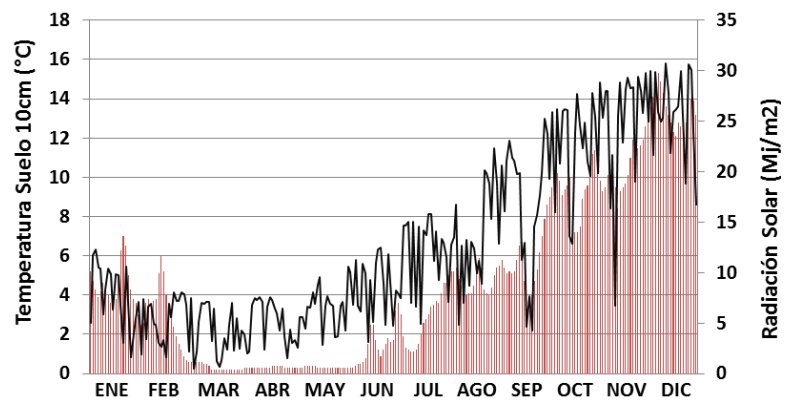

Figura $N^{\circ} 8$

TEMPERATURA DEL SUELO (10 CM) Y RADIACIÓN SOLAR DURANTE LA TEMPORADA 2018 INFORMACIÓN OBTENIDA DESDE LA ESTACIÓN METEOROLÓGICA VISTA HERMOSA 


\section{Suelos}

La caracterización de la fertilidad del suelo se describe en el Cuadro $N^{\circ} 5$.

Cuadro $\mathrm{N}^{\circ} 5$

FERTILIDAD INICIAL DE SUELOS MICRO Y MACRO ELEMENTOS

\begin{tabular}{|l|l|c|c|c|}
\hline \multirow{2}{*}{ Elementos } & \multirow{2}{*}{ Unidad } & \multicolumn{3}{|c|}{ Tratamientos } \\
\cline { 3 - 5 } & & Testigo & Silvopastoral & Pradera Natural \\
\hline $\mathbf{N}$ & $\mathrm{mg} / \mathrm{kg}$ & 32 & 26 & 57 \\
$\mathbf{P}$ & $\mathrm{mg} / \mathrm{kg}$ & 36,1 & 39,3 & 18,3 \\
$\mathbf{K}$ & $\mathrm{mg} / \mathrm{kg}$ & 446,2 & 373,7 & 523,1 \\
$\mathbf{S}$ & $\mathrm{mg} / \mathrm{kg}$ & 4,54 & 4,26 & 2,92 \\
$\mathbf{p H}$ & - & 6,26 & 6,38 & 6,10 \\
$\mathbf{M . O}$. & $\%$ & 22,9 & 20,0 & 23,3 \\
$\mathbf{C a}$ & $\mathrm{cmol}(+) / \mathrm{kg}$ & 16,26 & 15,89 & 14,49 \\
$\mathbf{M g}$ & $\mathrm{cmol}(+) / \mathrm{kg}$ & 4,03 & 3,65 & 3,82 \\
$\mathbf{K}$ & $\mathrm{cmol}(+) / \mathrm{kg}$ & 1,13 & 0,95 & 1,40 \\
$\mathbf{N a}$ & $\mathrm{cmol}(+) / \mathrm{kg}$ & 0,01 & 0,05 & 0,04 \\
$\mathbf{A l}$ & $\mathrm{cmol}(+) / \mathrm{kg}$ & 0,03 & 0,02 & 0,03 \\
$\mathbf{C I C E}$ & - & 21,48 & 20,56 & 19,79 \\
Sat. Al. & $\%$ & 0,13 & 0,11 & 0,15 \\
$\mathbf{B}$ & $\mathrm{Ppm}$ & 1,20 & 0,80 & 1,01 \\
\hline
\end{tabular}

El sitio posee niveles de nitrógeno adecuados, el fósforo disponible en este caso es alto, los valores de potasio disponible en general son más bien elevados, los niveles de bases de intercambio ( $\mathrm{Ca}, \mathrm{Mg}, \mathrm{K}, \mathrm{Na}$ ) son altos, hay una baja saturación de aluminio y los valores de $\mathrm{pH}$ están en el rango de ligeramente ácido y son característicos de esta zona. En consecuencia, se trata de suelos sin limitantes de fertilidad para el desarrollo del bosque.

Según IREN (1979) este tipo de suelos corresponden a la asociación Balmaceda y se ubica al norte del aeropuerto internacional hasta el rio Simpson, y por el Este a la altura del río Oscuro. Su posición fisiográfica corresponde a un plano de inundación, con relieve plano o casi plano, con ligeros a fuertes micro relieves producidos por la erosión eólica.

El drenaje es pobre a muy pobre, encontrándose áreas de drenaje muy restringido. Los suelos se han desarrollado a partir de sedimentos finos de origen fluviolacustres y lacustres, que han formado perfiles estratificados. Son suelos profundos, con moderada agregación en superficie y escaso desarrollo genético del perfil. Sus texturas se van haciendo finas en profundidad y el color dominante gris evidencia los problemas de drenaje del área.

Los suelos de esta asociación se han clasificado la mayor parte en Clase VI de capacidad de uso y Sub-Clase "w", no obstante, su condición de humedad, se encuentra severamente afectada por erosión eólica.

\section{Establecimiento de la Plantación Suplementaria de Ñirre}

En el mes de septiembre de 2018 se instaló la unidad de investigación que permitirá generar la propuesta de plantación suplementaria para la especie ñirre.

La unidad contempla tres situaciones bajo un gradiente lumínico, dado por un bosque testigo en el cual no se intervino el dosel, un segundo tratamiento en el que se aplicó un raleo por lo bajo extrayendo alrededor del $40 \%$ del área basal y un tercer tratamiento en terreno abierto o pradera naturalizada resultante de una extracción anterior del bosque para el uso ganadero del terreno.

Los tratamientos que contienen bosque corresponden a ñirrantales ubicados en la 
transición con la estepa patagónica, en una condición seca donde no existe influencia de napa freática.

\section{- Establecimiento de Clausuras y Cerco Perimetral}

Una vez seleccionado el sitio especifico del ensayo se estableció el cerco perimetral, que correspondió a un cerco tradicional, construido con postes de madera distanciados a $4 \mathrm{~m}$, cinco hebras de alambre ( 3 hebras de alambre liso y 2 hebras de alambre púas), donde finalmente se instaló una malla para evitar daños de liebres y ganado doméstico.
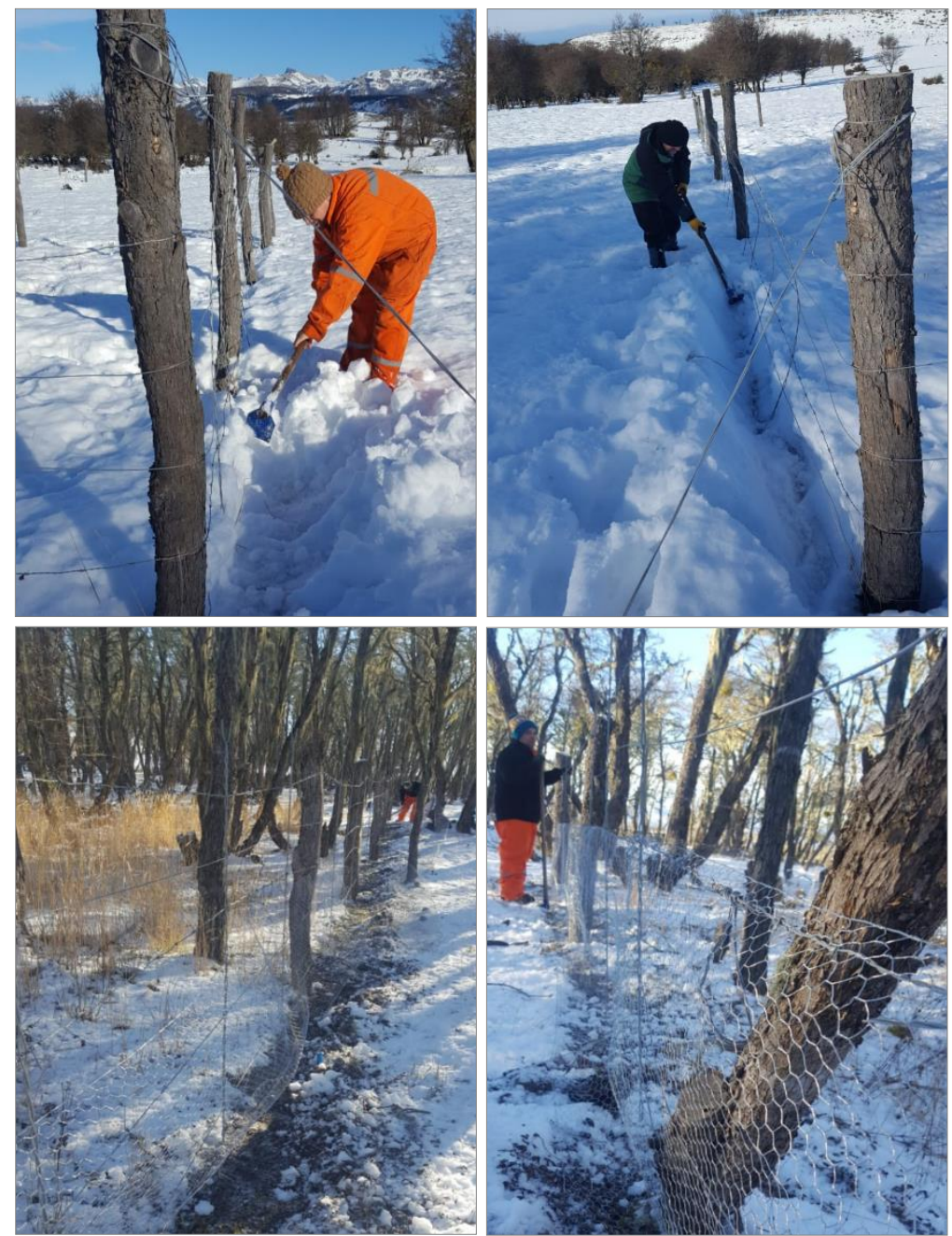

Figura $\mathbf{N}^{\circ} 9$

CONSTRUCCION DE CERCO PERIMETRAL 


\section{- Control de Malezas}

Posteriormente a la instalación del cerco se realizó el control de malezas de cada clausura. Se trata de sitios que han sido pastoreados durante años, por lo que el movimiento de semilla genera en cada temporada altos niveles de forraje, el cual es una potencial competencia para las plantas de ñirre. Para disminuir la competencia en las primeras temporadas se realiza el control de la cubierta forrajera de la pradera o sotobosque del ñirrantal. El control se realizó mediante un operador técnico empleando una motoguadaña (Figura $N^{\circ} 10$ ).
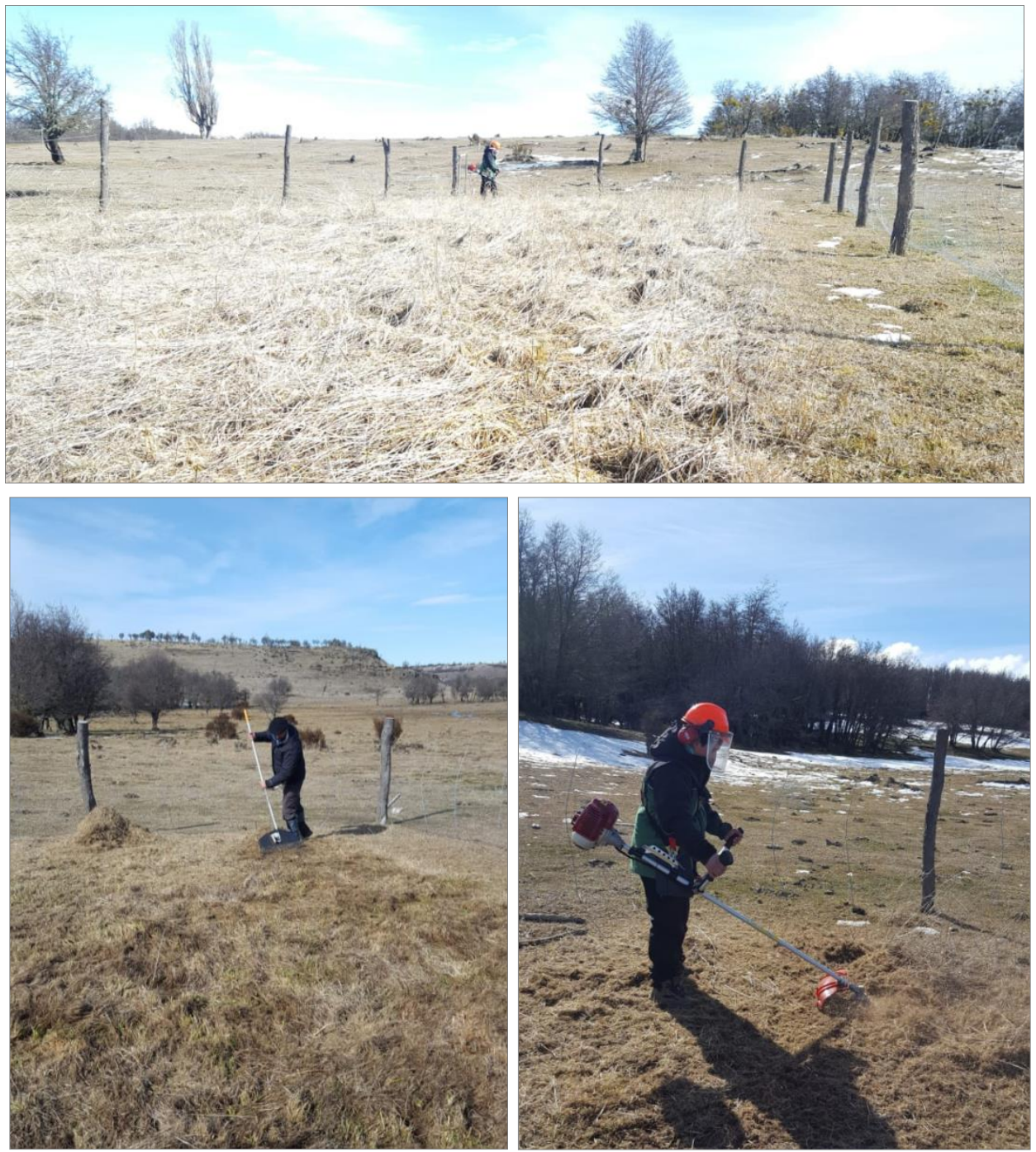

Figura $\mathrm{N}^{\circ} 10$

CONTROL DE MALEZAS 


\section{- Delimitación de los Clusters de Plantación}

En cada clausura se delimitaron 40 clusters de $1 \mathrm{~m}^{2}$ para cuya demarcación se utilizó cinta de marcación y tubos de PVC, tal como se indica en la Figura $\mathrm{N}^{\circ} 11$. Entre cada clusters se dejó una separación de 1,5 m con el fin de diferenciar al momento de medir las plantas.
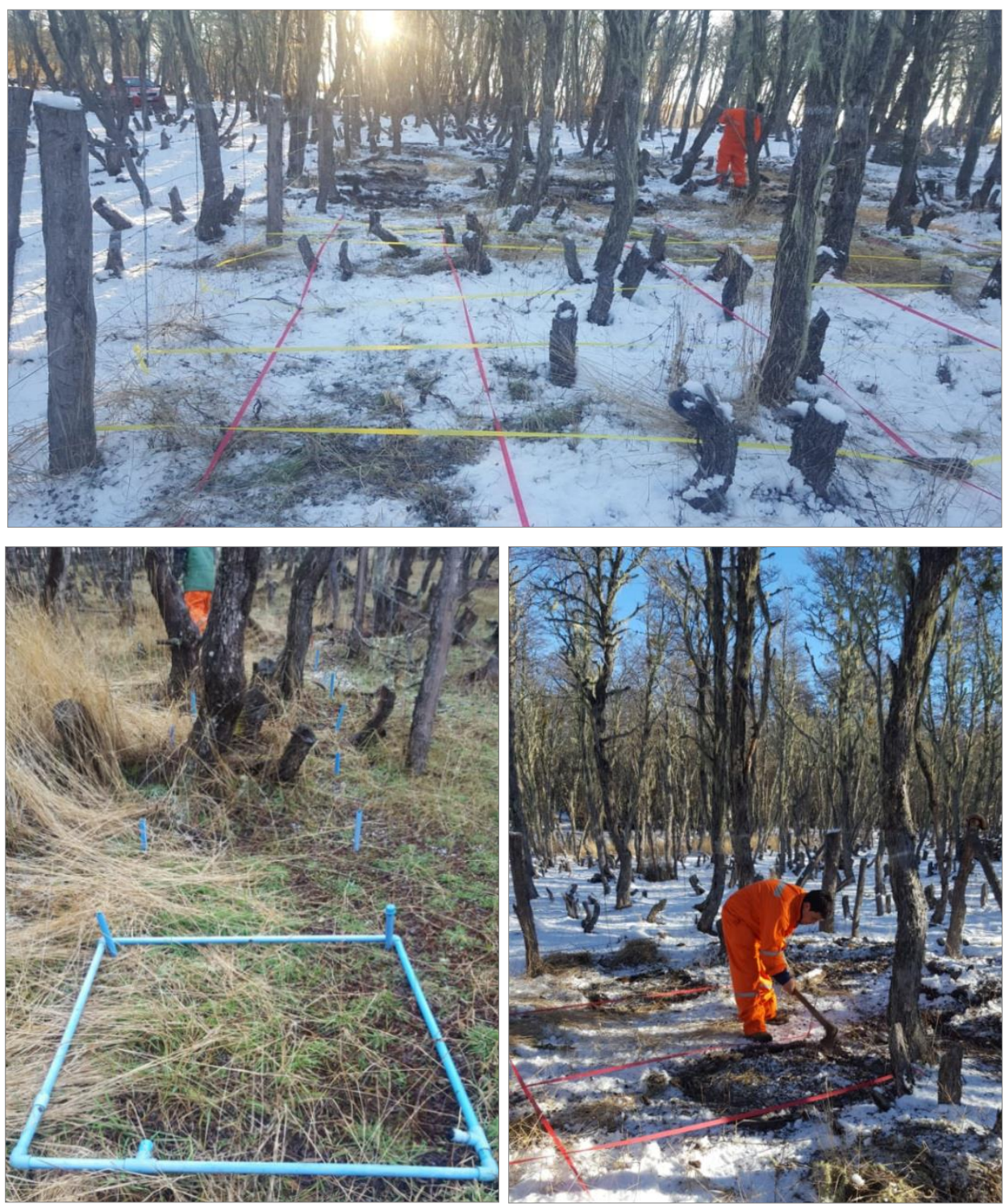

Figura $\mathrm{N}^{\circ} 11$

DELIMITACIÓN Y MARCACIÓN DE CLUSTERS 


\section{- $\quad$ Limpieza de los Clusters}

Delimitados los clusters al interior de las clausuras, se procedió a la limpieza del material vegetal de cada cluster ( $1 \mathrm{~m}^{2} \times 40$ cluster $\times 3$ clausuras $\times 3$ tratamientos). Esta labor se realizó en forma manual con la utilización de azadón.
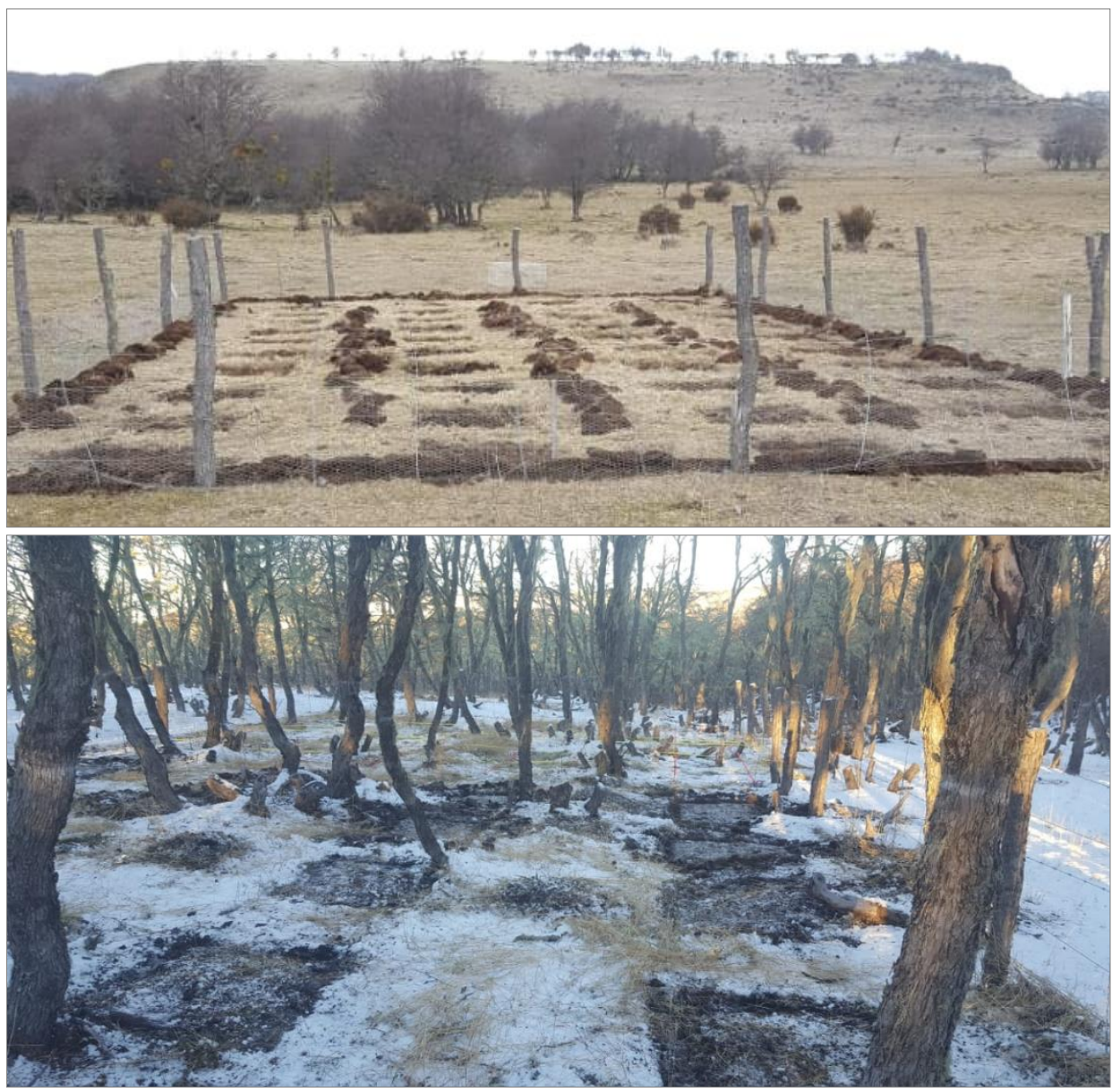

Figura $N^{\circ} 12$ LIMPIEZA DE LOS CLUSTERS

\section{Evaluación de Parámetros Morfológicos de la Plantación}

La evaluación de los parámetros morfológicos iniciales de las plantas de ñirre se efectuó durante el mes de noviembre de 2018.

Con la evaluación inicial de los parámetros morfológicos de las plantas se caracteriza el ensayo de plantación suplementaria desde su instalación. Con el fin de conocer el comportamiento de la especie bajo diferentes niveles de luminosidad. En esta evaluación se mantendrá una periodicidad de evaluaciones anuales. 
La evaluación consideró DAC $(\mathrm{mm})$ y $\mathrm{Ht}(\mathrm{m})$ para cada cluster en los tratamientos Bosque, Bosque raleado y Pradera naturalizada, incorporándose además la variable con y sin control de competencia de malezas.
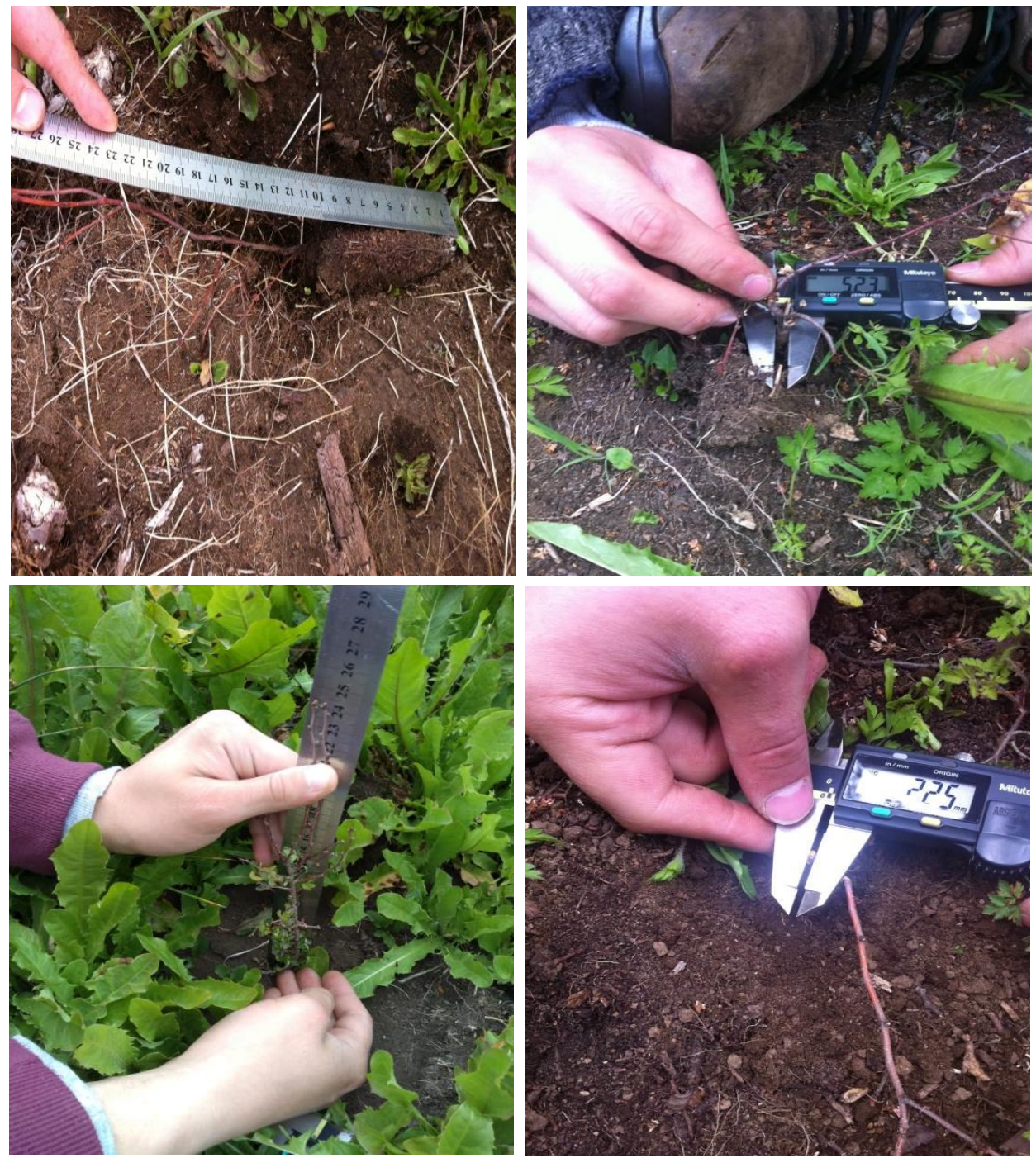

Figura $N^{\circ} 13$

EVALUACIÓN DE PARÁMETROS MORFOLÓGICOS DE PLANTAS

\section{Bosque sin Manejo}

La medición inicial de los parámetros morfológicos de plantas establecidas en el tratamiento Bosque sin Manejo, dio como resultado un DAC medio de 2,88 \pm 1,0 $\mathrm{mm}$ y una altura promedio de $16,73 \pm 7,5 \mathrm{~cm}$ (Figuras $\mathrm{N}^{\circ} 14 \mathrm{y} \mathrm{N}^{\circ} 15$ ). 

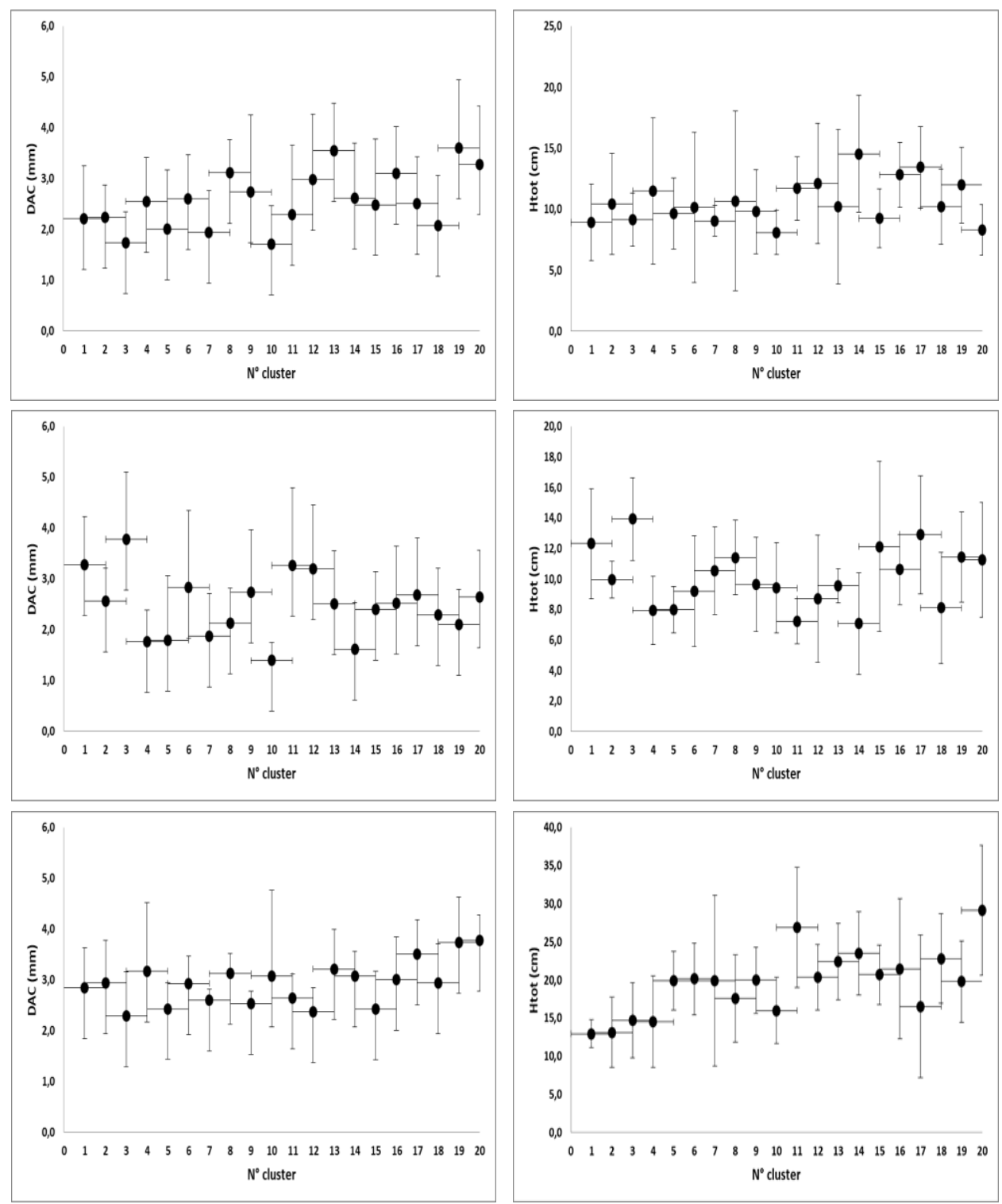

Figura $\mathrm{N}^{\circ} 14$

DIÁMETRO DE CUELLO (DAC) Y ALTURA TOTAL (HTOT) PLANTAS BOSQUE SIN MANEJO Y SIN CONTROL MALEZAS 

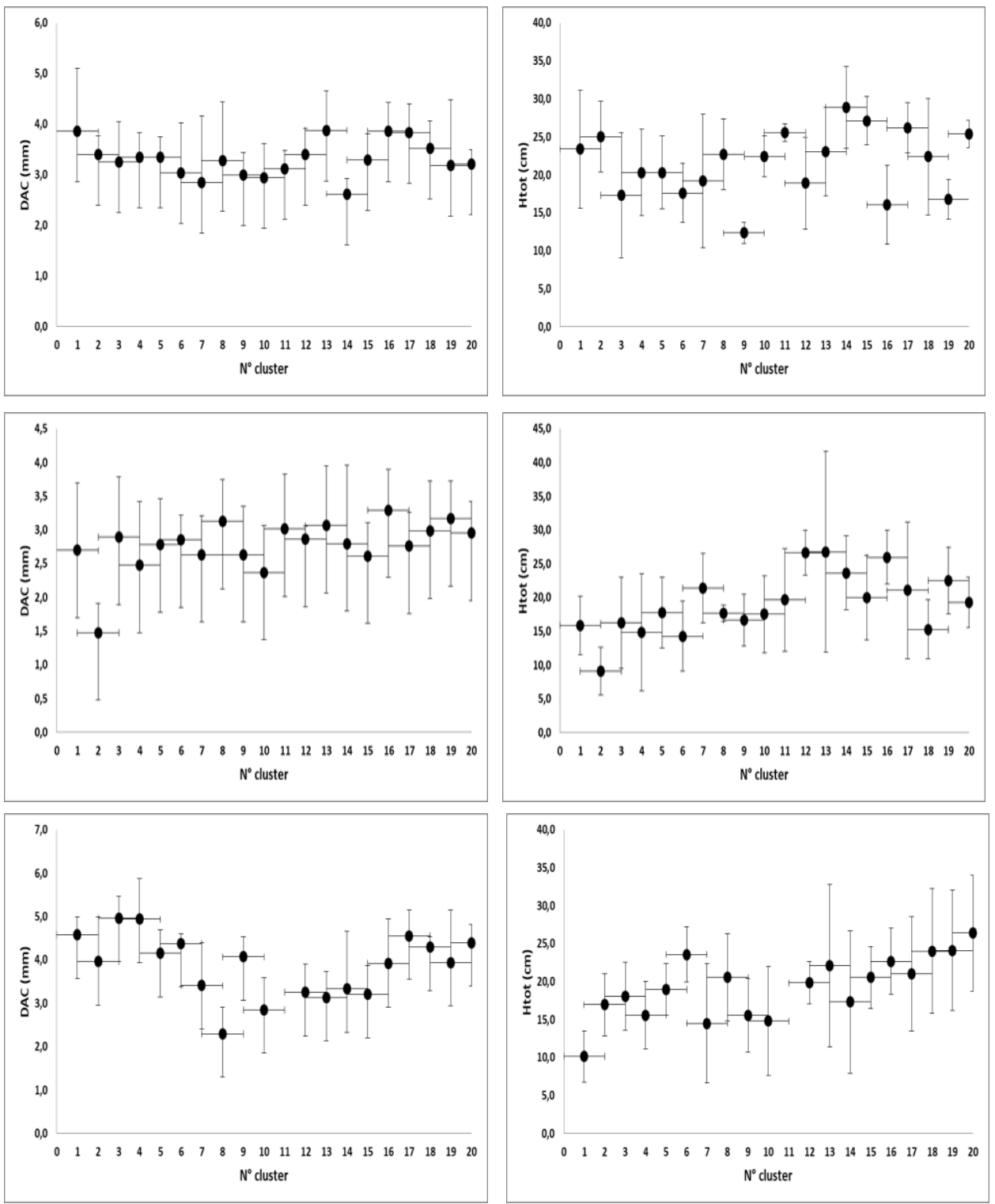

Figura $\mathrm{N}^{\circ} 15$

DIÁMETRO DE CUELLO (DAC) Y ALTURA TOTAL (HTOT) PLANTAS BOSQUE SIN MANEJO Y CON CONTROL MALEZAS 


\section{Bosque con Manejo}

La medición inicial de los parámetros morfológicos de plantas establecidas en el tratamiento Bosque con Manejo dio como resultado un DAC medio de 3,52 $\pm 0,94 \mathrm{~mm}$ y una altura promedio de $21,77 \pm 7,11 \mathrm{~cm}$ (Figuras $\mathrm{N}^{\circ} 16$ y $\mathrm{N}^{\circ} 17$ ).
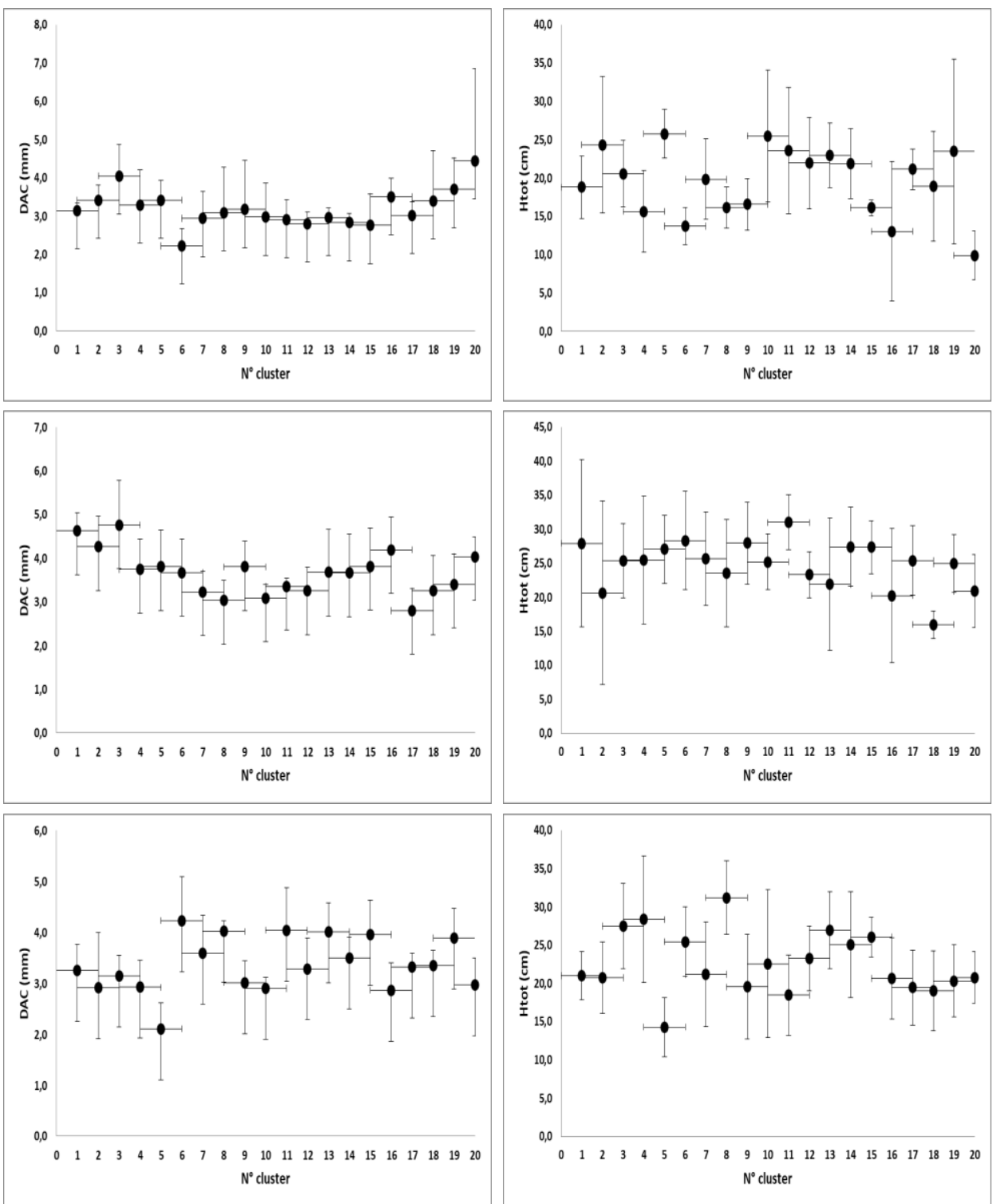

Figura $\mathrm{N}^{\circ} 16$

DIÁMETRO DE CUELLO (DAC) Y ALTURA TOTAL (HTOT) PLANTAS BOSQUE CON MANEJO Y SIN CONTROL MALEZA 

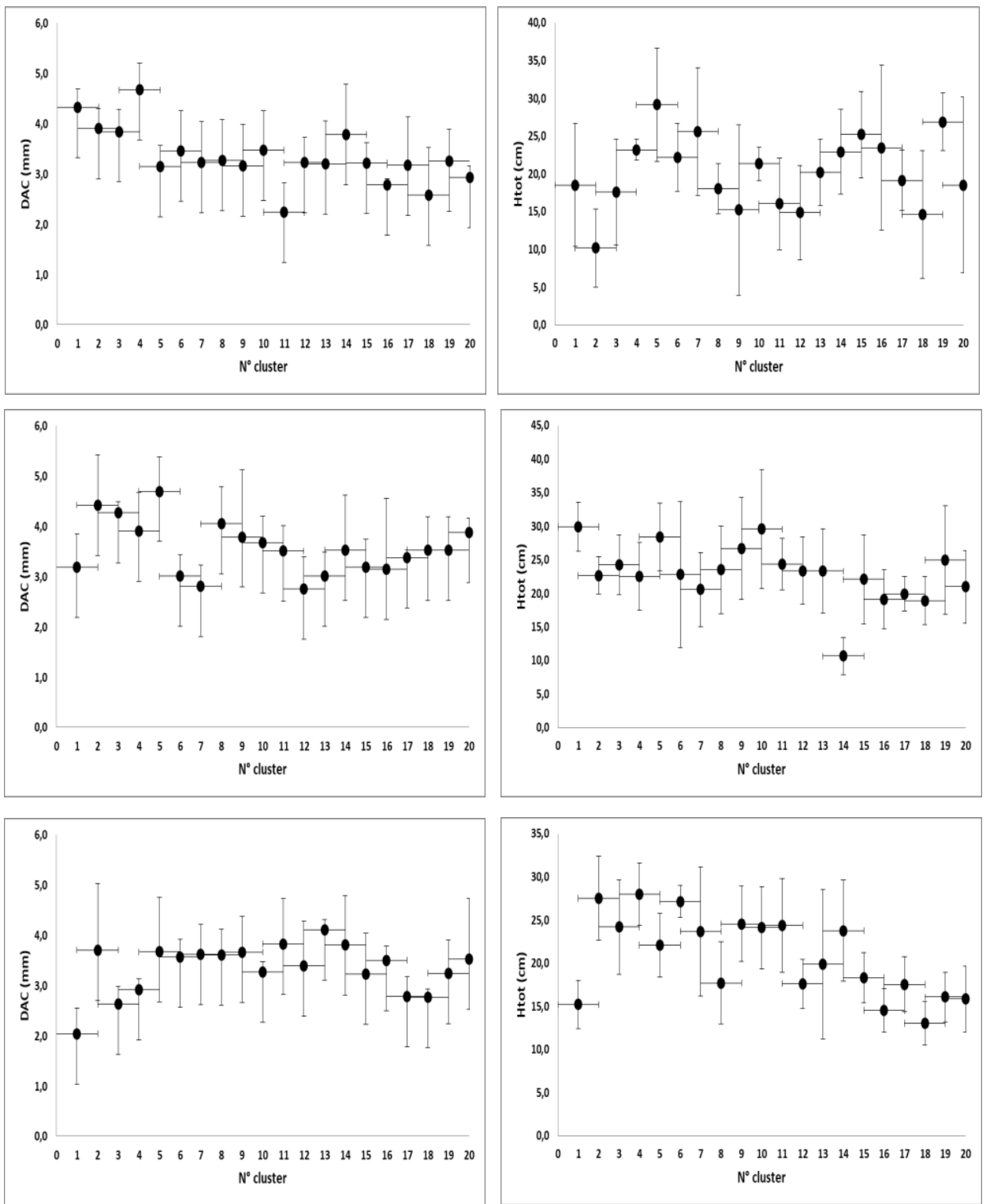

Figura $\mathrm{N}^{\circ} 17$

DIÁMETRO DE CUELLO (DAC) Y ALTURA TOTAL (HTOT) PLANTAS

BOSQUE CON MANEJO Y CON CONTROL MALEZA 


\section{Pradera Naturalizada}

La medición inicial de los parámetros morfológicos de plantas establecidas en el tratamiento Pradera Naturalizada dio como resultado un DAC medio de $3,20 \pm 1,33 \mathrm{~mm}$ y una altura promedio de $21,55 \pm 7,13 \mathrm{~cm}$ (Figuras $\mathrm{N}^{\circ} 18$ y $\left.\mathrm{N}^{\circ} 19\right)$.
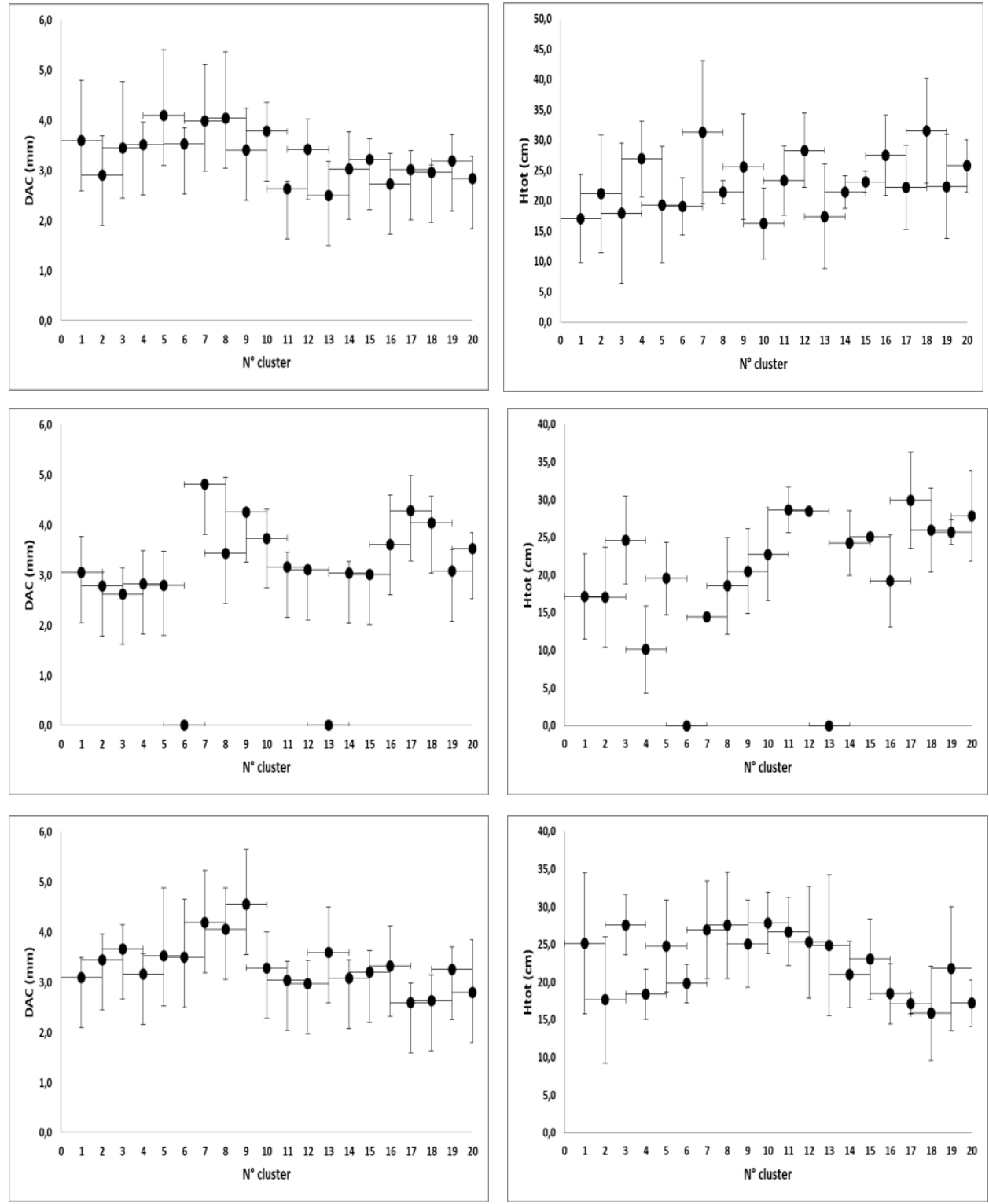

Figura $\mathrm{N}^{\circ} 18$

DIÁMETRO DE CUELLO (DAC) Y ALTURA TOTAL (HTOT) PLANTAS

PRADERA NATURALIZADA Y CON CONTROL MALEZA 

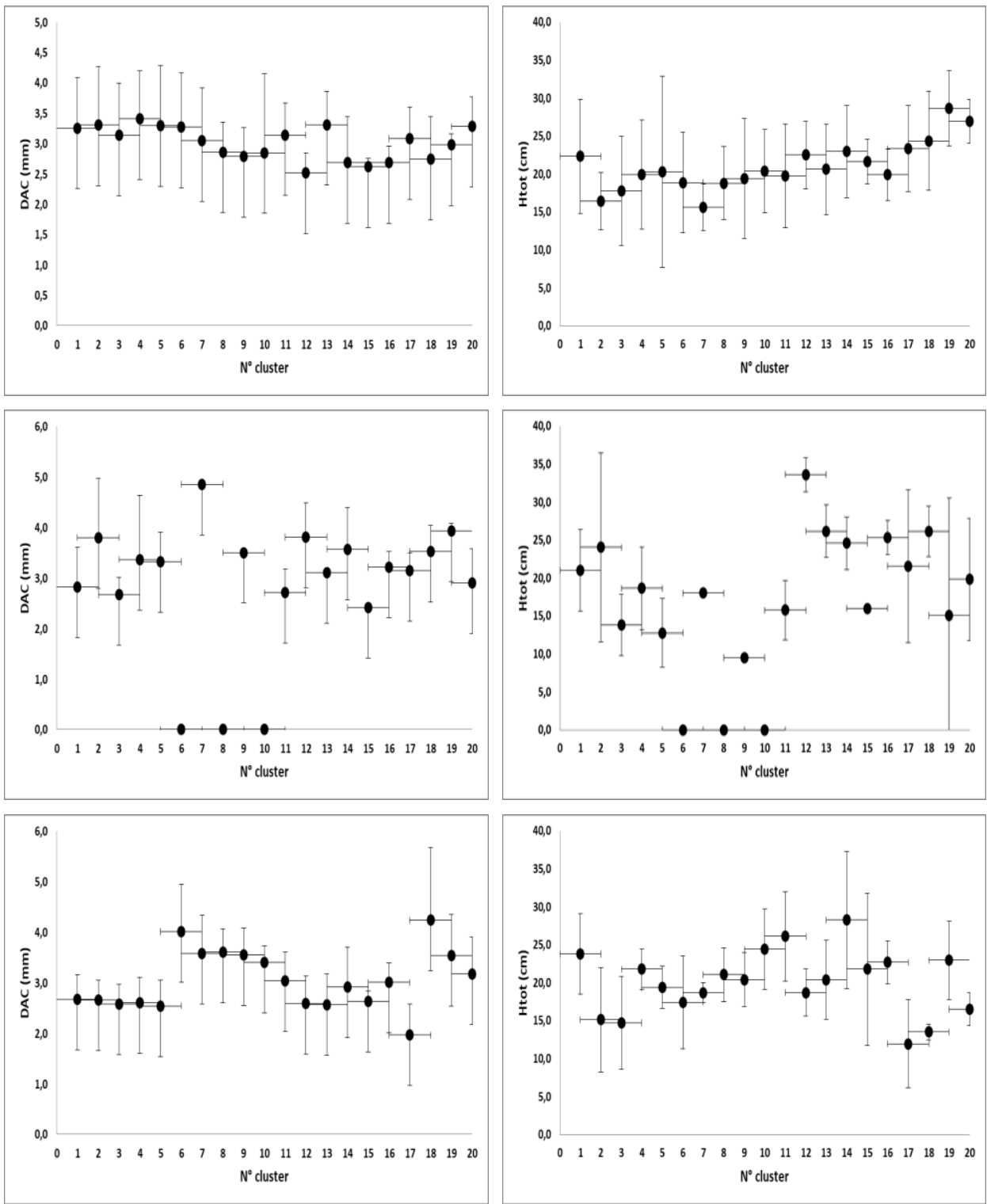

Figura $\mathrm{N}^{\circ} 19$

DIÁMETRO DE CUELLO (DAC) Y ALTURA TOTAL (HTOT) PLANTAS PRADERA NATURALIZADA Y SIN CONTROL MALEZA 


\section{CONCLUSIONES}

El sitio de ensayo fue caracterizado en cuanto a clima y suelos, también se caracterizó el bosque en los tratamientos que lo incluyen, se estableció el ensayo en 2018 según programado y se efectuó una primera evaluación de las plantas en cada tratamiento como línea base para mediciones posteriores de crecimiento.

El ensayo será evaluado anualmente desde 2019 en cuanto a supervivencia y crecimiento de las plantas por tratamiento y con la información a reunir se espera formular una propuesta de plantación suplementaria apropiada para bosques alterados de ñirre.

\section{REFERENCIAS}

Armesto, J. J.; Casassa, I. and Dollenz, O., 1992. Age structure and dynamics of Patagonian Beech forests in Torres del Paine National Park, Chile. Vegetation 98, 13 - 22.

Donoso, C., 1974. Manual de identificación de especies leñosas del bosque húmedo de Chile, CONAF, Santiago, $168 \mathrm{p}$.

Donoso, C.,1987. Variación natural en especies de Nothofagus en Chile. Bosque: 8 (2), 85 - 97.

Donoso, C., 2006. Las Especies arbóreas de los Bosques Templados de Chile y Argentina. Autoecología. Marisa Cúneo Ediciones, Valdivia, Chile. 678 p.

Hoffmann, A., 1997. Flora silvestre de Chile, Zona Araucana: Árboles, arbustos y enredaderas leñosas. Ediciones Fundación Claudio Gay, Santiago, Chile. 258 pp.

IREN - CORFO. 1979. Perspectivas de desarrollo de los recursos de la Región de Aisén del General Carlos lbáñez del Campo: diagnóstico del conocimiento de geología y minería. Coihaique, 67 pág.

Ivancich, H. S., 2013. Tesis doctoral: Relaciones entre la estructura forestal y el crecimiento del bosque de Nothofagus antarctica en gradientes de edad y calidad de sitio. Director: G. Martínez Pastur, Codirectora: M.V. Lencinas.

Navarro Cerrillo, R.; Rosenfeld, M.; Pérez-Aranda, J.; Padrón, E.; Guzmán, J.; Hernández, R.; y González, C., 2008. Evaluación de la mortalidad de bosques de ñirre (Nothofagus antarctica) en la Patagonia chilena mediante imágenes Landsat TM y ETM+. Bosque 29(1), 65 - 73.

Premoli, A., 1991. Morfología y capacidad germinativa en poblaciones de Nothofagus antarctica (Forster) Oerst del noroeste andino patagónico. Bosque 12(2): 53-59.

Ramírez, C.; Correa, M.; Figueroa, H. y San Martin, J., 1985. Variación del hábito y hábitats de Nothofagus antarctica en el centro-sur de Chile. Bosque 6: 55-73.

Rodríguez, R.; Mathei, O. y Quezada, M., 1983. Flora Arbórea de Chile. Editorial Universitaria. Concepción, Chile. 408 pp.

Salinas, J.; Acuña, B.; Uribe, A. y Koch, L., 2015. Estudio de regeneración natural en bosques de Nothofagus antarctica (Forster) Oerst. (ñirre) bajo pastoreo doméstico en la Región de Aysén. Instituto Forestal, Ministerio de Agricultura. Coyhaique, Chile. 50 p.

Salinas, J.; Ivancich, H.; Acuña, B. y Solis, L., 2016. Caracterización y clasificación de los bosques de ñirre (Nothofagus antarctica (Forster) Oerst.) de la comuna de Coyhaique, como herramienta para la toma de decisiones en el manejo silvícola. Instituto Forestal, Ministerio de Agricultura. Coyhaique, Chile. 51 p.

Salinas, J., 2016. Experiencia de manejo silvopastoral en dos renovales coetáneos de Nothofagus antarctica (G.Forst.) Oerst. (Ñirre) en la Región de Aysén, Chile. Revista Ciencia e Investigación Forestal, CIFOR, Vol. 22 № 1, Pág.: 37-50.

Salinas, J., Peri, P., Hepp, C. y Acuña, B. 2017. Sistemas silvopastorales en bosques de ñirre (Nothofagus antarctica (G. Forst.) Oerst.) en la Región de Aysén. Instituto Forestal. Coyhaique, Chile. 58 p. 
Veblen, T.; Donoso, C.; Kitzberger, T. and Rebertus, A., 1996. Ecology of southern Chilean and Argentinean Nothofagus forests. Pages 293-353 in: T.T. Veblen, R.S. Hill, and J. Read (eds.), Ecology and Biogeography of Nothofagus Forests. Yale University Press.

Vidal, R. y Premoli, A., 2004. Variación en Nothofagus antarctica (Forster) Oerst. (Ñirre o Nire) En: Donoso C., L. Gallo, A. Premoli \& R. Ipinza (Eds.) Variación intraespecífica en las especies arbóreas de los bosques templados de Chile y Argentina. Santiago: Editorial Universitaria. 